Article

\title{
A New Insight into the Comonomer Effect through NMR Analysis in Metallocene Catalysed Propene-co-1-Nonene Copolymers
}

\author{
Qiong Wu ${ }^{1}\left(\right.$, Alberto García-Peñas ${ }^{2,3}$ (D) , Rosa Barranco-García ${ }^{4}$, María Luisa Cerrada ${ }^{4}$, \\ Rosario Benavente ${ }^{4}$, Ernesto Pérez ${ }^{4}$ and José Manuel Gómez-Elvira ${ }^{4, *}$ \\ 1 School of Engineering, Hong Kong University of Science and Technology, Clear Water Bay, \\ 999077 Kowloon, Hong Kong \\ 2 College of Materials Science and Engineering, Shenzhen Key Laboratory of Polymer Science and Technology, \\ Guangdong Research Centre for Interfacial Engineering of Functional Materials, Nanshan District Key \\ Laboratory for Biopolymers and Safety Evaluation, Shenzhen University, Shenzhen 518060, China \\ 3 Key Laboratory of Optoelectronic Devices and Systems of Ministry of Education and Guangdong Province, \\ College of Optoelectronic Engineering, Shenzhen University, Shenzhen 518060, China \\ 4 Instituto de Ciencia y Tecnología de Polímeros (ICTP-CSIC), Juan de la Cierva 3, 28006 Madrid, Spain \\ * Correspondence: elvira@ictp.csic.es; Tel.: +34-912-587-524
}

Received: 4 June 2019; Accepted: 22 July 2019; Published: 31 July 2019

\begin{abstract}
The "comonomer effect" is an intriguing kinetic phenomenon in olefin copolymerization that still remains without a detailed explanation. It typically relates to the rate of enhancement undergone in ethylene and propene catalytic polymerization just by adding small fractions of an alpha-olefin. The difficulty lies in the fact that changes caused by the presence of the comonomer in reaction parameters are so conspicuous that it is really difficult to pin down which of them is the primary cause and which ones are side factors with marginal contribution to the phenomenon. Recent investigations point to the modification of the catalyst active sites as the main driving factor. In this work, the comonomer effect in the metallocene copolymerization of propene and 1-nonene is analysed and correlated to the comonomer role in the termination of the chain-growing process. The associated termination mechanisms involved furnish most of chain-free active sites, in which the selective interaction of the comonomer was proposed to trigger the insertion of monomers. A thorough characterisation of chain-end groups by means of the ${ }^{1} \mathrm{H}$ NMR technique allows for detailing of specific transfer processes, ascribed to comonomer insertions, as well as evidencing the influence of the growing chain's microstructure over the different termination processes available.
\end{abstract}

Keywords: polypropene copolymers; comonomer effect; metallocene catalysts; microstructure; NMR analysis

\section{Introduction}

Incorporation of small quantities of a comonomer, mostly an $\alpha$-olefin, into ethylene or propene polymerizations usually enhances the kinetics of the process. This is what is known as the comonomer effect. The phenomenon has been reported in Ziegler-Natta, Phillips, and metallocene catalysts with a large variety of comonomers [1-34] and great concern exists in explaining its true nature, since it has important consequences from a production point of view [16].

Much effort has been devoted to understanding the reasons for this surprising kinetic change, which seems to depend on every copolymerization parameter. Diverse variables have been claimed as driving ones, however the fact is that, to date, there is no definite explanation. A brief overview of them is presented next. 
Many authors have claimed solubility enhancement of copolymer chains and subsequent improvement in mass transfer processes as the key factor in Ziegler-Natta and supported metallocene catalysts $[2,7,15,22,24-26,31,34-43]$, however although an easier diffusion of the monomer through less crystalline phases may contribute to a rate enhancement, no satisfactory correlation has been found with crystallinity degree or copolymer solubility [44].

Most explanations are, however, focussed on the modification of both the quality and concentration of active catalyst sites. In fact, many works agree with this assumption as a crucial piece in the puzzle $[5,10-12,15,21,23,24,27,29,45-49]$. For example, fracturing of inorganic particles and polymer aggregates in heterogeneous and homogeneous catalysis, respectively, has been claimed to exert a primary role $[1,2,34,36]$, however the fact that the comonomer effect has been observed in systems both without particle fragmentation and completely dissolved suggests that this factor is not essential.

Another proposed explanation is related to an increment of active sites by activation of dormant species. This would be possible through displacement of the equilibrium set by inactive catalyst-donor complexes towards active catalyst- $\alpha$-olefin ones [5,20,50-54].

As far as the active site's quality is concerned, Sacchi et al. explored the modification of the metallocene shielding by changing solvent polarity and co-catalyst bulkiness $[49,55]$. They found that if the active site was somehow unshielded, the kinetics of the comonomer insertion sped up and the activity improved.

Another factor influencing the active site accessibility is comonomer coordination itself, which has been suggested to enhance spacing between the metal atom and the counteranion. This was proposed by some authors $[10,29,32]$, who suggested that the polymerization rate would be higher for small comonomers due to their inferior steric hindrance. The role of comonomer as a solvating molecule of the active site has also been highlighted by Kryzhanovskii et al. [19].

More recently, some works on $\mathrm{Cr}$ (II) Phillips type catalysts have shown that modification of the active centre through selective interaction with $\alpha$-olefin does occur, and this must be a determinant for a rate enhancement [4,44]. These results support the "trigger mechanism" [12], which proposes the simultaneous coordination of two monomers at the active site, one of them being selectively occupied by the $\alpha$-olefin, which would play as the trigger species.

Difficulties encountered in the search of a conclusive explanation arise from the fact that most reaction parameters are somewhat altered and it is not easy at all to determine whether the observed kinetic enhancement is mainly dependent on a single factor or on the cooperative contribution of a number of them. However, a certainty does arise from all these works: namely, it is quite plausible that modifications undergone by the catalyst active centre are mostly involved, with the possible assistance of other factors.

Notwithstanding the above detailed concurrence of factors, there is a common denominator for almost all cases. The molecular weight of the copolymer is lower than the one observed for the homopolymer, since the comonomer seems to influence not only propagation rate, but chain transfer as well $[3,7,9,29,56,57]$. The immediate consequence is that the steady state concentration of chain-free initiating sites is higher and that might enhance the copolymerization kinetics if it is assumed that the specific interaction of initiating metallocene sites with the comonomer triggers the first insertion [44]. Some previous results correlating catalyst activity and chain-transfer termination mechanisms in the copolymerization of propene with 1-pentene support such a hypothesis [57].

In this work, the metallocene copolymerization of propene with 1-nonene is studied at different temperatures. The correlation between catalyst activity and chain transfer efficiency of inserted comonomers is analysed, as well as termination mechanisms lying behind, in order to check the correlation previously found in poly(propylene-co-1-pentene) copolymers. 


\section{Materials and Methods}

\subsection{Synthesis of Copolymers and Homopolymers}

The homo and copolymerization reactions were performed under inert conditions after careful purification of the initial reactants. Toluene (Merck) and 1-nonene $\left(C_{9}\right.$, Acros) were dried by refluxing over metallic sodium and further distillation under nitrogen. Nitrogen (Praxair 3X) and propylene (Praxair 2.5) were purified by flowing through oxygen-trap columns and molecular sieves before using. Ethanol and $\mathrm{HCl}$ employed were Aroca, 96\%, and VWR, 37\%, respectively. The metallocene catalyst rac-dimethylsilylbis(1-indenyl) zirconium dichloride $\left(\mathrm{Me}_{2} \mathrm{Si}\left(\mathrm{C}_{9} \mathrm{H}_{6}\right)_{2} \mathrm{ZrCl}_{2}\right)$ was supplied by Strem, and the co-catalyst MMAO was supplied by Aldrich as a solution in toluene (MMAO-12, 7 wt. \% in $\mathrm{Al}$ ).

Polypropene homopolymers and poly(propene-co-1-nonene) copolymers were prepared in a Büchi glass ecoclave $(500 \mathrm{~mL})$ at polymerization temperatures $\left(T_{\mathrm{pol}}\right)$ of $-5,10,25,40$, and $60{ }^{\circ} \mathrm{C}$ in $250 \mathrm{~mL}$ toluene and with an initial propene pressure of 1.5 bar. Runs were carried out at 1-nonene feeding molar fractions ranging between 0 and 0.34 . The reactions were started by incorporation of the metallocene precursor, which was previously activated with the cocatalyst. The final (Al)/(Zr) molar ratio was 1925. The reaction was finished at a $10 \%$ propene consumption by adding $5 \mathrm{~mL}$ of ethanol. Subsequently, samples were precipitated with a mixture of ethanol and $\mathrm{HCl}$ (30:1). The so-precipitated polymers were stirred overnight, filtered, washed with ethanol, and finally dried under vacuum at room temperature.

Poly-1-nonene homopolymers were also obtained in toluene solution by following an identical procedure and conditions to those used for the copolymerizations. In this case, 0.09 moles of $C_{9}$ were injected into the reactor and a pressure of 1.5 bar of nitrogen was used instead of propene. The samples were isolated by removing the toluene in a rotary evaporator, then dissolving with 1-pentene and extracting residues from MMAO and catalyst with acidified water. Finally, after washing with pure water, the 1-pentene and the unreacted 1-nonene were removed by evaporation under vacuum at $120^{\circ} \mathrm{C}$.

Volumes of $C_{9}$ incorporated into the reactor were directly used to calculate feeding molar fractions without performing any correction due to the temperature. It was checked that the comonomer loss in the solution was negligible in all cases, according to the corresponding vapour pressure at the different tested polymerization temperatures, $T_{\mathrm{pol}}$ [58], and was calculated from Raoult's law. As for the propene, the molar fraction in the reaction medium was estimated by means of the relationship given by Ferreira et al. for solutions in toluene [59].

\subsection{Identification of Samples}

Copolymer samples will hereinafter be named as C9PP, followed by the polymerization temperature and the closest integer value for the $\mathrm{C}_{9} \mathrm{~mol} \%$ content. For instance, C9PP-5_2 stands for a copolymer obtained at $-5{ }^{\circ} \mathrm{C}$, of which 1-nonene content is $2 \mathrm{~mol} \%$. In the case of homopolymers, samples were simply identified as PP for polypropylene and as poly $\mathrm{C}_{9}$ for poly-1-nonene. Similarly to copolymers, the corresponding polymerization temperature was indicated next. With this, PP40 and poly $\mathrm{C}_{9} 40$ stand, respectively, for polypropylene and poly-1-nonene samples synthesised at $40^{\circ} \mathrm{C}$.

\subsection{NMR Analysis}

${ }^{1} \mathrm{H}$ and ${ }^{13} \mathrm{C}$ NMR experiments as well as ${ }^{13} \mathrm{C}-\mathrm{DEPT},{ }^{1} \mathrm{H}-{ }^{13} \mathrm{C}$ HSQC, and ${ }^{1} \mathrm{H}-{ }^{1} \mathrm{H}$ TOCSY were carried out at $80^{\circ} \mathrm{C}$ with a Bruker Avance III HD-400 spectrometer (Billerica, MA, USA) from solutions of the samples in 1,1,2,2-tetrachloroethane- $d_{2}(70 \mathrm{mg} / 0.7 \mathrm{~mL})$. The only exceptions were the PP samples, of which ${ }^{1} \mathrm{H}$ and ${ }^{13} \mathrm{C}$ NMR spectra were obtained with a Bruker Avance III/500 $(125.76 \mathrm{MHz})$ at $100{ }^{\circ} \mathrm{C}$. ${ }^{1} \mathrm{H}$ NMR spectra of the samples were performed by accumulating 64 scans. The proton analysis was always carried out prior to the ${ }^{13} \mathrm{C}$ one, so as to avoid the appearance of signals caused by processes associated with long residence times of the ${ }^{13} \mathrm{C}$ NMR analysis, like degradation and isomerisation. Chemical shifts of ${ }^{1} \mathrm{H}$ signals were referred to that of the 1,1,2,2-tetrachloroethane- $d_{2}$ at $6.00 \mathrm{ppm}$. 
2D ${ }^{1} \mathrm{H}-{ }^{1} \mathrm{H}$ TOCSY spectra were obtained by performing 16 scans with a delay time of $2 \mathrm{~s}$, an acquisition time of $0.256 \mathrm{~s}$, a spectral width of $3997 \mathrm{~Hz}$ in both dimensions, 1024 data points in F1 and $\mathrm{F} 2$, a mixing time of $80 \mathrm{~ms}$, and a $90^{\circ}$ pulse width $(12 \mu \mathrm{s})$.

${ }^{13} \mathrm{C}$ NMR spectra were recorded with broad band proton decoupling using a $24,038 \mathrm{~Hz}$ spectral window, an acquisition time of $1 \mathrm{~s}$, a relaxation delay of $5 \mathrm{~s}$, and a pulse angle of $45^{\circ}(5 \mu \mathrm{s})$. A minimum of 8000 scans were recorded. Chemical shifts for ${ }^{13} \mathrm{C}$ signals were referred to those of the 1,1,2,2-tetrachloroethane- $d_{2}$ at $74.00 \mathrm{ppm}$.

A $5 \mathrm{~s}$ delay time was found to be adequate to assure complete relaxation of ${ }^{13} \mathrm{C}$ spins. It was checked by performing the ${ }^{13} \mathrm{C}$ NMR spectrum of the highest comonomer content sample (CP60_12) with a $10 \mathrm{~s}$ delay time. Differences observed in microstructure, both in composition and in configuration, were within the experimental error (see Table 1 in Results and Table S1 provided in Supplementary Materials).

Table 1. Characteristics of polymerization runs and samples.

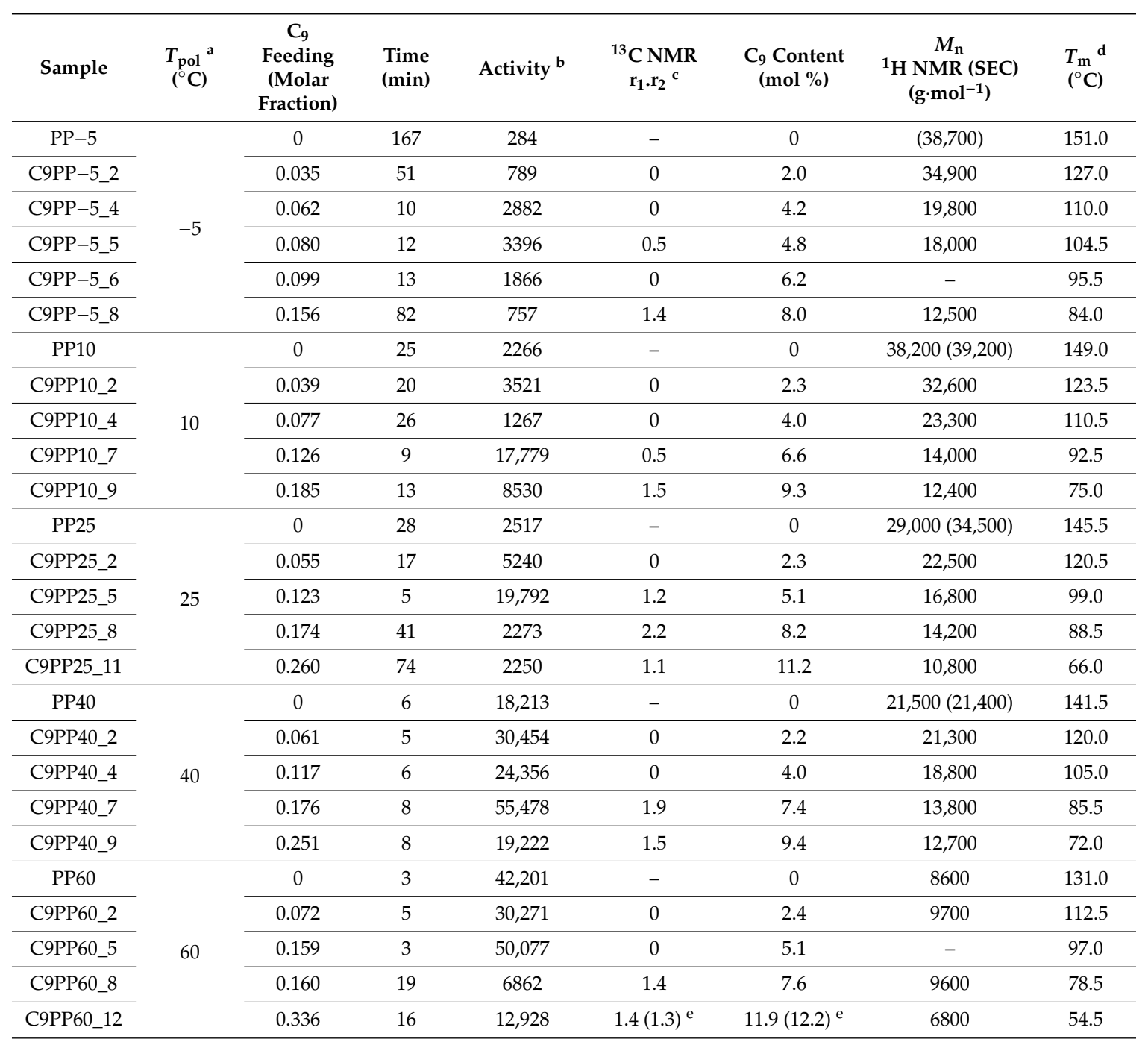

(a) Temperature of polymerization; (b) Activity units are: $\mathrm{Kg} \cdot \mathrm{mol}^{-1}{ }_{[\mathrm{Zr}]} \mathrm{mol}^{-1}[\mathrm{Prop}] \mathrm{h}^{-1}$; (c) Values of zero for the reactivity ratio product correspond to the exclusive presence of isolated $C_{9}$ unit; (d) Values obtained by Differential Scanning Calorimetry (DSC); (e) Values obtained from a ${ }^{13} \mathrm{C}$ NMR spectrum with a $10 \mathrm{~s}$ delay time.

${ }^{13} \mathrm{C}$ DEPT NMR for one of the poly-1-nonene samples was obtained using the Bruker deptsp135 sequence, pulse widths of 10 and $14 \mu$ s for ${ }^{1} \mathrm{H}$ and ${ }^{13} \mathrm{C}$, respectively, a spectral window of $16,129 \mathrm{~Hz}$, and accumulating 10,000 scans. 
$2 \mathrm{D}^{1} \mathrm{H}_{-}{ }^{13} \mathrm{C}$ DEPT-HSQC spectra were performed using a $90^{\circ}$ pulse $\left(14\right.$ and $10 \mu \mathrm{s}$ for ${ }^{1} \mathrm{H}$ and ${ }^{13} \mathrm{C}$, respectively), $6.39 \mathrm{MHz}$ spectral width in the ${ }^{1} \mathrm{H}$ dimension and $16.59 \mathrm{MHz}$ in the ${ }^{13} \mathrm{C}$ dimension, $0.2 \mathrm{~s}$ acquisition time, and $2 \mathrm{~s}$ relaxation delay.

\subsection{Size Exclusion Chromatography (SEC)}

The SEC analysis of PP samples was performed in a Waters GPC/V 2000 (Milford, MA, USA) equipped with refractive index and viscometer detectors. A set of three columns of the PL Gel type was used with 1,2,4-trichlorobenzene at $145^{\circ} \mathrm{C}$ as the solvent and $1 \mathrm{~mL} / \mathrm{min}$ flow rate. The injection volume was $200 \mu \mathrm{L}$ and the equipment was calibrated with narrow molecular mass distribution standards of polystyrene.

\subsection{Differential Scanning Calorimetry (DSC)}

The melting temperatures $\left(T_{\mathrm{m}}\right)$ were measured in a TA Q100 Instrument calorimeter (New Castle, DE, USA) connected to a cooling system and calibrated with indium and zinc. The samples were heated from $-45^{\circ} \mathrm{C}$ to either $160^{\circ} \mathrm{C}$ for the copolymers or $180^{\circ} \mathrm{C}$ for the PP samples, at a heating rate of $10{ }^{\circ} \mathrm{C} \cdot \mathrm{min}^{-1}$. They were subsequently cooled down to $-45^{\circ} \mathrm{C}$, also at $10^{\circ} \mathrm{C} \cdot \mathrm{min}^{-1}$, and finally heated up again to 160 or $180^{\circ} \mathrm{C}$. The values of $\mathrm{T}_{\mathrm{m}}$ were taken from the maximum of the endotherm peak obtained after the second heating scan. The results are shown in Table 1.

\section{Results}

\subsection{Microstructure and Molecular Weight}

The microstructure in the composition of copolymers was obtained from the analysis of ${ }^{13} \mathrm{C} N \mathrm{NR}$ spectra. Assignments were made according to literature $[60,61]$ and they are shown in Figure 1 for the particular case of samples obtained at $60^{\circ} \mathrm{C}$. They were identified in the figure using the established nomenclature for branched polyolefin copolymers [62]. The corresponding identifiers for the different carbon nuclei are shown in Scheme 1.

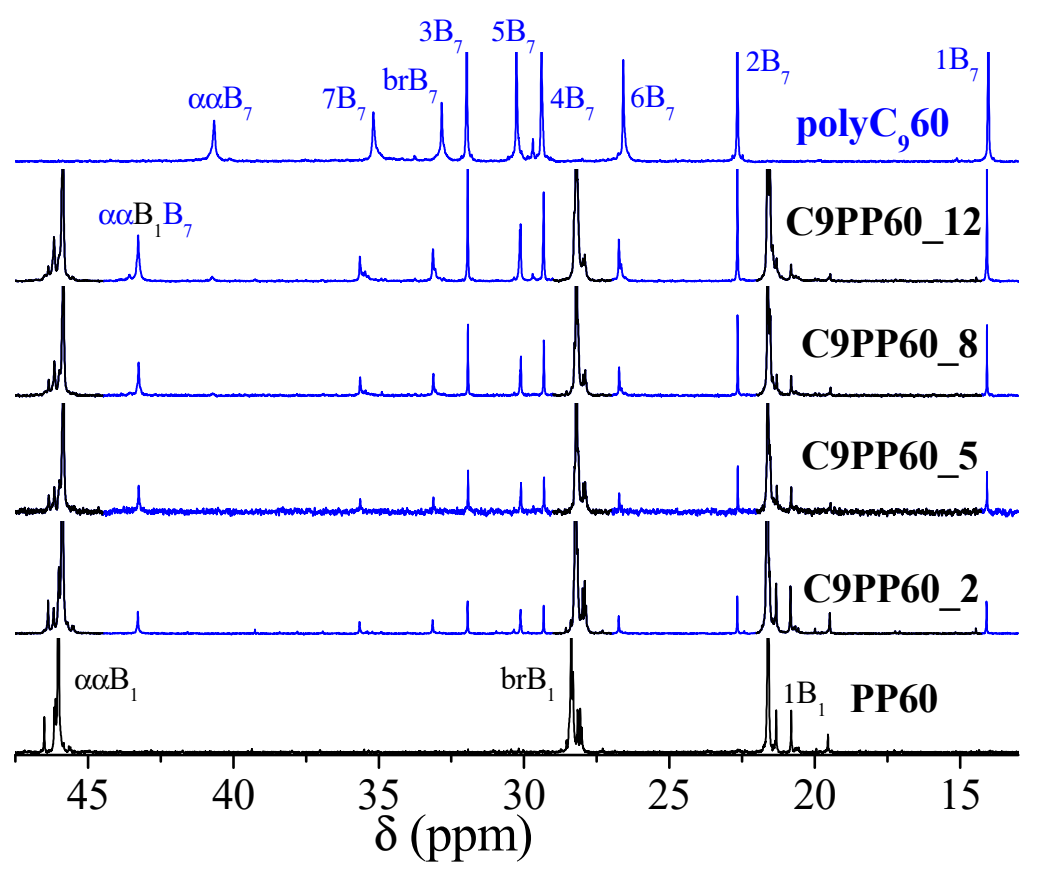

Figure 1. ${ }^{13} \mathrm{C}$ NMR spectra for the samples obtained at $60{ }^{\circ} \mathrm{C}$.

The relative molar content of 1-nonene $\left(\mathrm{C}_{9}\right)$ of the different copolymers was estimated from the integrals of the methyl signals $1 B_{7}$ and $1 B_{1}$. No significant differences were found between these 
so-calculated values and those ones obtained from the relationship between methine integrals (signals $\mathrm{brB}_{7}$ and $\mathrm{brB}_{1}$ ). The comonomer content of the samples is reported in Table 1.

Additionally, the reactivity ratio product $\left(\mathrm{r}_{1} \cdot \mathrm{r}_{2}\right)$ was calculated from the comonomer distribution at the diad level using appropriate relationships between ${ }^{13} \mathrm{C}$ NMR integrals [6]. The results are also listed in Table 1 and show that $r_{1} \cdot r_{2}$ values are not far away from unity. This allows us to confirm that the samples are random copolymers.

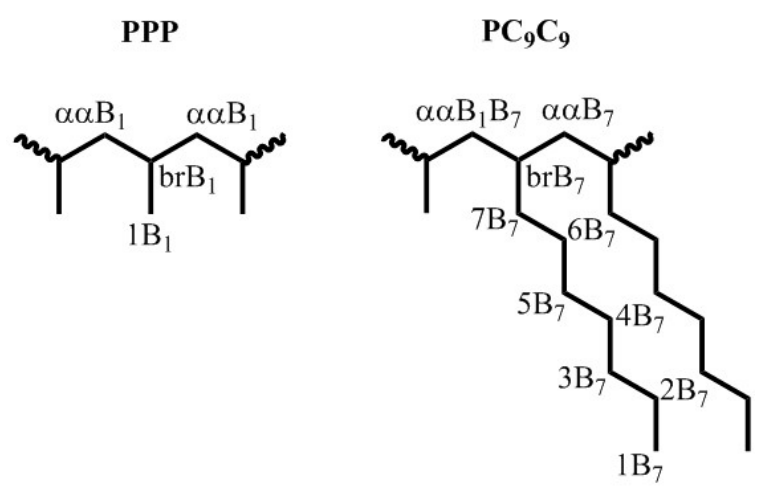

Scheme 1. Nomenclature of carbon nuclei in the homo-propene triad (PPP) and in a copolymer triad $\left(\mathrm{PC}_{9} \mathrm{C}_{9}\right)$.

Finally, the tacticity of propene sequences was estimated from the methyl region $\left(1 \mathrm{~B}_{1}\right.$ in Scheme 1 : $19.4-22.0 \mathrm{ppm})$ at the pentad level [60]. The isotactic average length of propene sequences $\left(n_{1}\right)$ was assessed by taking into account any kind of isotactic sequence interruption, either $C_{9}$ insertion or both stereo and regio-misinsertions of propene [63].

Results are summarized in Table S1, provided as supplementary data. This table reveals that propene isotacticity, tracked by means of (mmmm) pentads, decreases as $T_{\text {pol }}$ rises from -5 to $60^{\circ} \mathrm{C}$.

The qualitative and quantitative analysis of chain-end double bonds was performed by ${ }^{1} \mathrm{H} N \mathrm{NM}$. It revealed different olefin species, which are shown in Figure 2 for samples obtained at $40{ }^{\circ} \mathrm{C}$ as an example. The species displayed are vinylidenes from 4.65 to $4.85 \mathrm{ppm}\left(V d\right.$ and $\left.V d_{1}\right)$, vinyls from 4.9 to $5.12 \mathrm{ppm}$, and from 5.78 to $5.95 \mathrm{ppm}(V)$, trisubstituted olefins from 5.12 to $5.30 \mathrm{ppm}\left(T\right.$ and $\left.T_{1}\right)$ and vinylenes from 5.30 to $5.62 \mathrm{ppm}\left(V_{\mathrm{y}}\right)$. The assignment of every signal is indicated in the picture by the corresponding acronym (see Scheme 2 ) and it can be seen that isobutenyl groups $\left(T_{1}\right)$ are only found in the PP homopolymer.

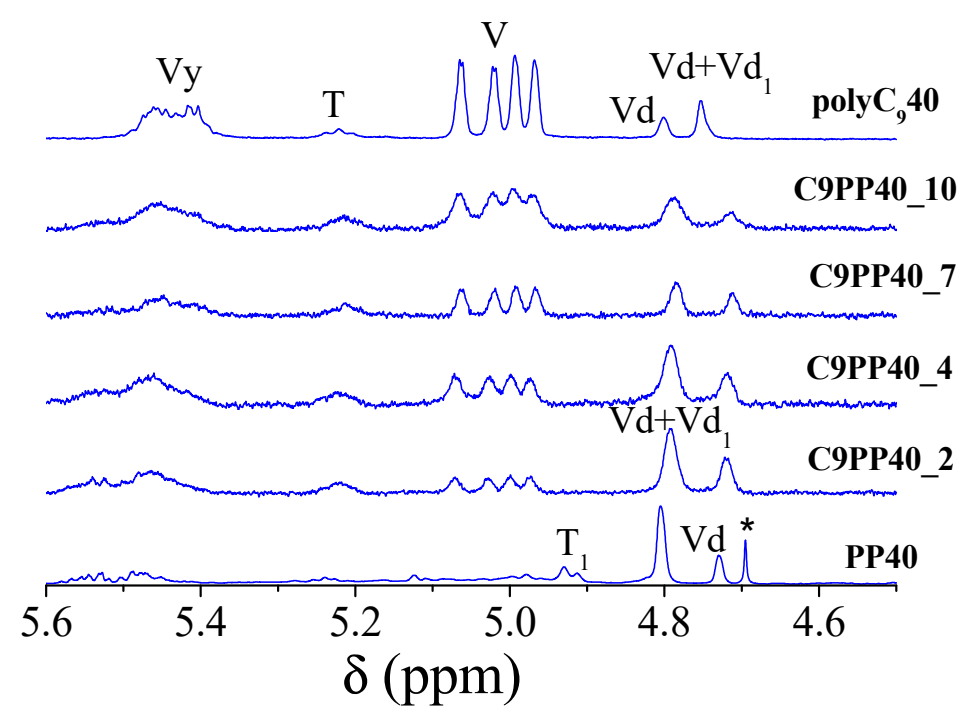

Figure 2. Olefinic window of ${ }^{1} \mathrm{H}$ NMR spectra for samples obtained at $40{ }^{\circ} \mathrm{C}$. ( ${ }^{*}$ solvent impurity). 


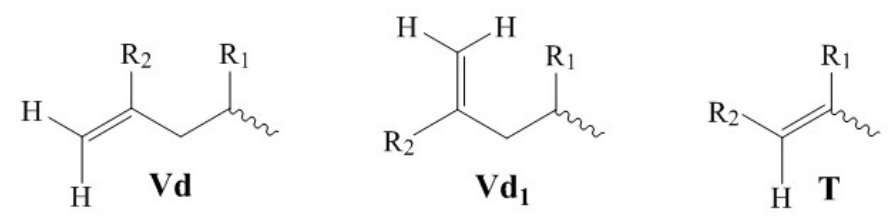<smiles>[R]C(C)C/C=C\[TlH]</smiles><smiles>[R]C=C(C([R1])C)C(C)C</smiles><smiles>[R]C=CC([R1])C(C)C</smiles><smiles>CC=CCC</smiles>

Scheme 2. Chain-end groups.

As far as $V d_{1}$ olefins are concerned, their protons overlap with the low-field signal of the $V d$ doublet [64-66] in the case of PP and $C_{9}$ copolymers (see the higher intensity of the $V d+V d_{1}$ signal in copolymer samples in Figure 2). Consequently, it is the high-field signal of $V d$ groups that yields the content of these species, and it has been subtracted from the $V d+V d_{1}$ integral to estimate the population of $V d_{1}$ olefins. The situation seems to be different in the poly-1-nonene (top ${ }^{1} \mathrm{H} \mathrm{NMR}$ spectrum in Figure 2) because the asymmetry shown by both $V d$ signals is just the opposite. The ${ }^{1} \mathrm{H}_{-}{ }^{13} \mathrm{C}$ DEPT-HSQC spectrum of poly-1-nonene obtained at $40{ }^{\circ} \mathrm{C}$ (represented in Figure 3) confirms the overlapping of two different olefinic protons at $4.75 \mathrm{ppm}$, which are ascribed to terminal and internal vinylidenes species.

Molecular weights were calculated from the relationship between ${ }^{1} \mathrm{H}$ NMR integrals corresponding to protons of main-chain methines and olefin groups, according to the next expression:

$$
\begin{aligned}
& M n=\frac{\int_{1.42}^{1.75}(\mathrm{CH}) d \delta}{1 / 2\left[\int_{4.94}^{5.11}(V) d \delta+\int_{5.33}^{5.60}(V y) d \delta\right]+\int_{4.67}^{4.76}(V d) d \delta+\int_{5.15}^{5.27}(T) d \delta+\int_{4.87}^{4.94}\left(T_{1}\right) d \delta} \\
& \times\left[126 \cdot f\left(C_{3}\right)+42 \cdot f\left(C_{9}\right)\right]
\end{aligned}
$$

where $V d, V, V_{\mathrm{y}}, T$, and $T_{1}$ correspond to the intensity of the NMR signal for the different chain-end double bonds, according to acronyms given in Scheme 2, and $f\left(\mathrm{C}_{3}\right)$ and $f\left(\mathrm{C}_{9}\right)$ correspond to molar fractions of propene and 1-nonene in the copolymer, respectively. Integrals were performed on the indicated chemical shift ranges $(\delta)$, given in ppm.

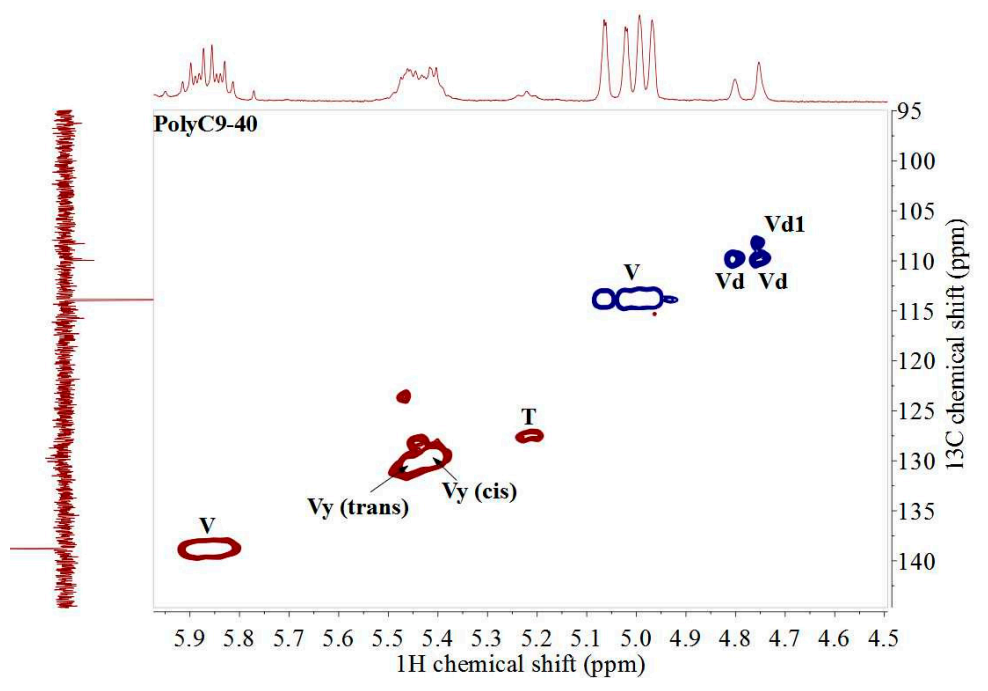

Figure $3 .{ }^{1} \mathrm{H}^{-13} \mathrm{C}$ DEPT-HSQC spectrum of the sample polyC $\mathrm{C}_{9} 40$. 
It was assumed that metallocene polymerization yields only one terminal double bond every chain [64]. Therefore, all olefin species were taken for such calculus, except for in-chain vinylidenes (see $V d_{1}$ groups in Scheme 2). The values are collected in Table 1.

\subsection{Evolutions of $C_{9}$ Insertion, Catalyst Activity, and Molecular Weight with the $C_{9}$ Feeding Fraction}

The insertion of $\mathrm{C}_{9}$ into PP chains seems to depend on the polymerization temperature, as can be deduced from Figure 4. This graph shows how the copolymer is enriched in $C_{9}$ as long as $T_{\text {pol }}$ decreases. For instance, at a $\mathrm{C}_{9}$ feeding fraction of 0.15 , the difference in $\mathrm{C}_{9}$ content already fetches about $4 \mathrm{~mol} \%$ between copolymerizations performed at 60 and $-5{ }^{\circ} \mathrm{C}$.

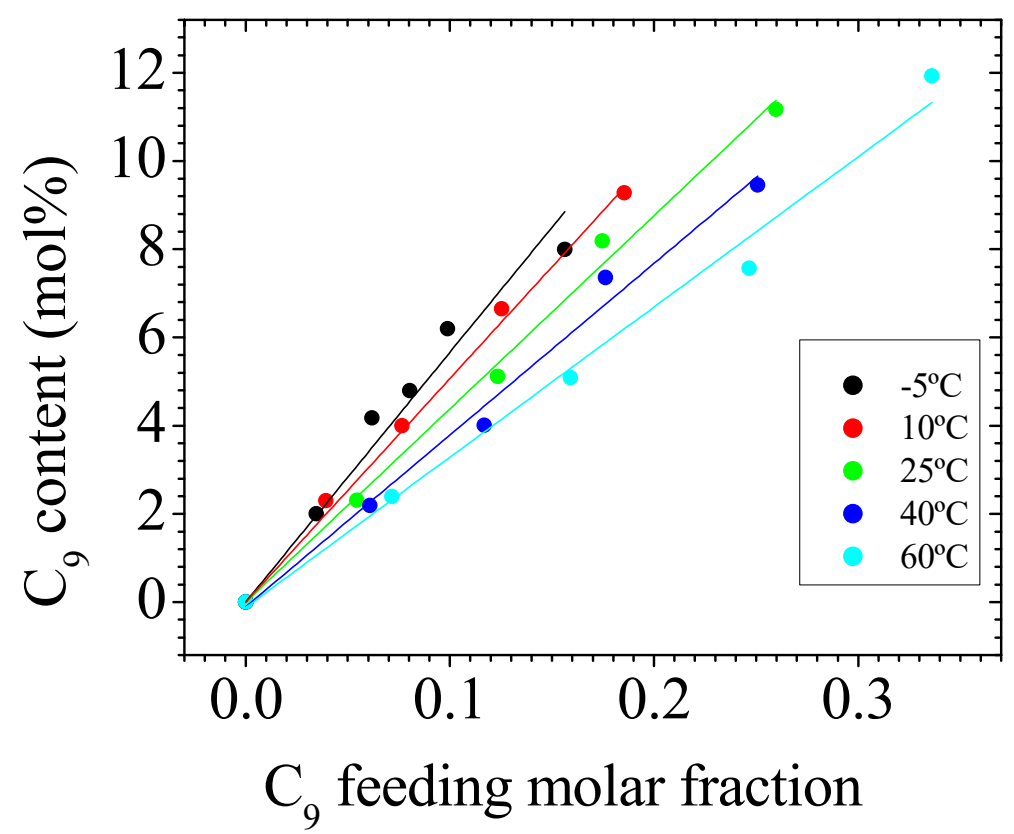

Figure 4. Variation of the $C_{9}$ content in the copolymers with the $C_{9}$ feeding molar fraction at the different $T_{\text {pol }}$. A colour code is inserted into the figure.

The activities for the different copolymerization runs are collected in Table 1, where it can be observed that values increase with $T_{\text {pol }}$ and go through a maximum in every series. Even though this rise with temperature is expected, the detailed analysis in Figure 5 unravels an aspect that aids in understanding the comonomer effect. As a matter of fact, the relative activities, calculated by taking the corresponding propene homopolymerization's activity as a reference, make evident that copolymerization kinetics depend on $T_{\text {pol }}$. Furthermore, the figure first shows that the maximum appears at lower $C_{9}$ feeding ratios as $T_{\text {pol }}$ decreases. Secondly, the phenomenon is relatively much more conspicuous as the temperature diminishes. 


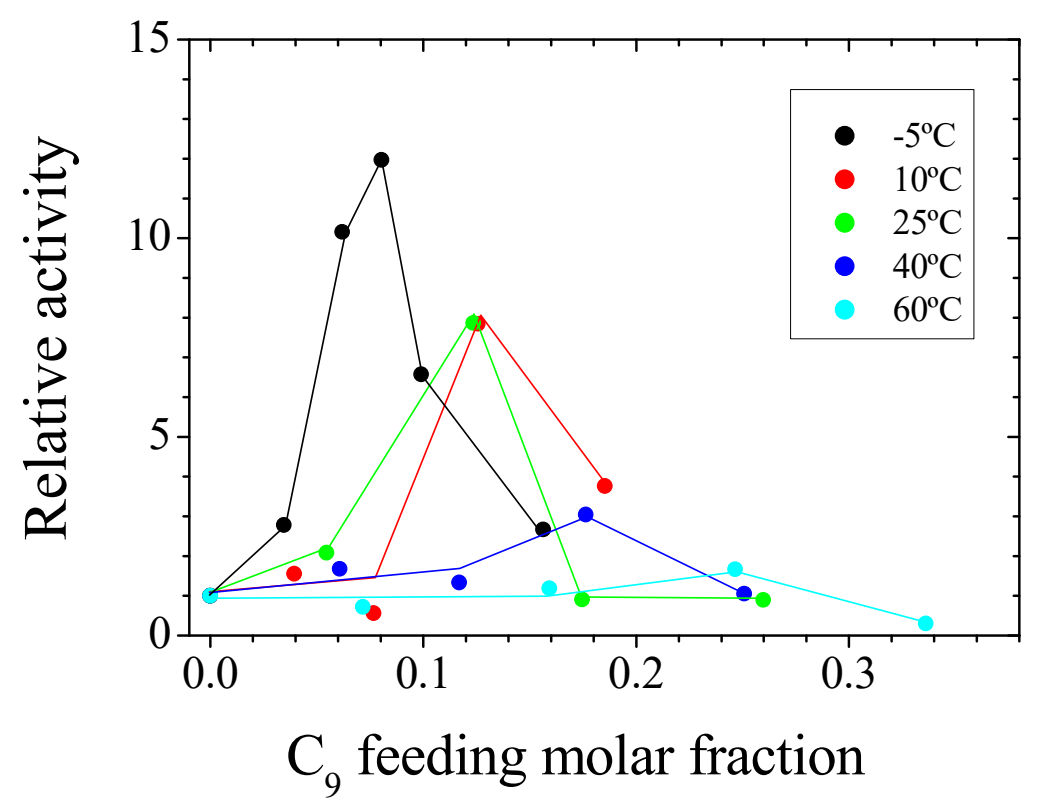

Figure 5. Evolution of relative activities with the $\mathrm{C}_{9}$ feeding molar fraction. Polymerization runs are distinguished by the colour code inserted.

The kinetic enhancement undergone by the copolymerization, due to the presence of $C_{9}$ in the medium, is also associated with diminution of molecular weights, as is shown in Figure 6. It is evident from this graph that chain size decreases with $C_{9}$ insertion and that the reduction is more effective at lower $T_{\text {pol }}$. In other words, $C_{9}$ must be involved in a chain shortening process, which seems to be promoted when $T_{\text {pol }}$ decreases.

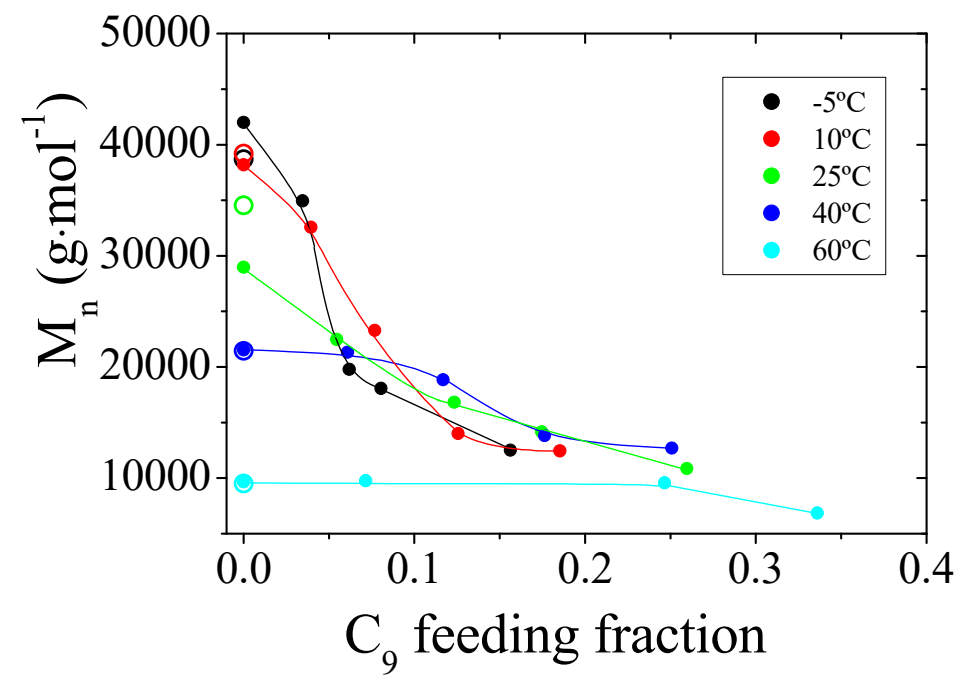

Figure 6. Variation of the number average molecular weight $\left(M_{n}\right)$ with the $C_{9}$ feeding molar fraction. Open symbols: $M_{\mathrm{n}}$ from SEC; solid symbols: $M_{\mathrm{n}}$ from ${ }^{1} \mathrm{H}$ NMR. A colour code is inserted into the figure.

\subsection{Evolution of Olefin Species with the $C_{9}$ Feeding Fraction}

The relative contribution of every terminal olefin was found to depend on $T_{\text {pol }}$ rather than on copolymer composition. This fact is illustrated in Figure 7, which shows the ${ }^{1} \mathrm{H}$ NMR window under study for copolymers of comparable compositions obtained at different $T_{\mathrm{pol}}$. It is quite evident that, firstly, important differences arise not only from the relative intensities of signals, but also from the comparison of the $V_{\mathrm{y}}$ contours; and, secondly, that $V_{\mathrm{y}}$ profiles match analogous signals in their 
corresponding poly $\mathrm{C}_{9}$ samples. The evolution of all signals will be comparatively tracked next in order to assess the relative importance of the different termination pathways involved.

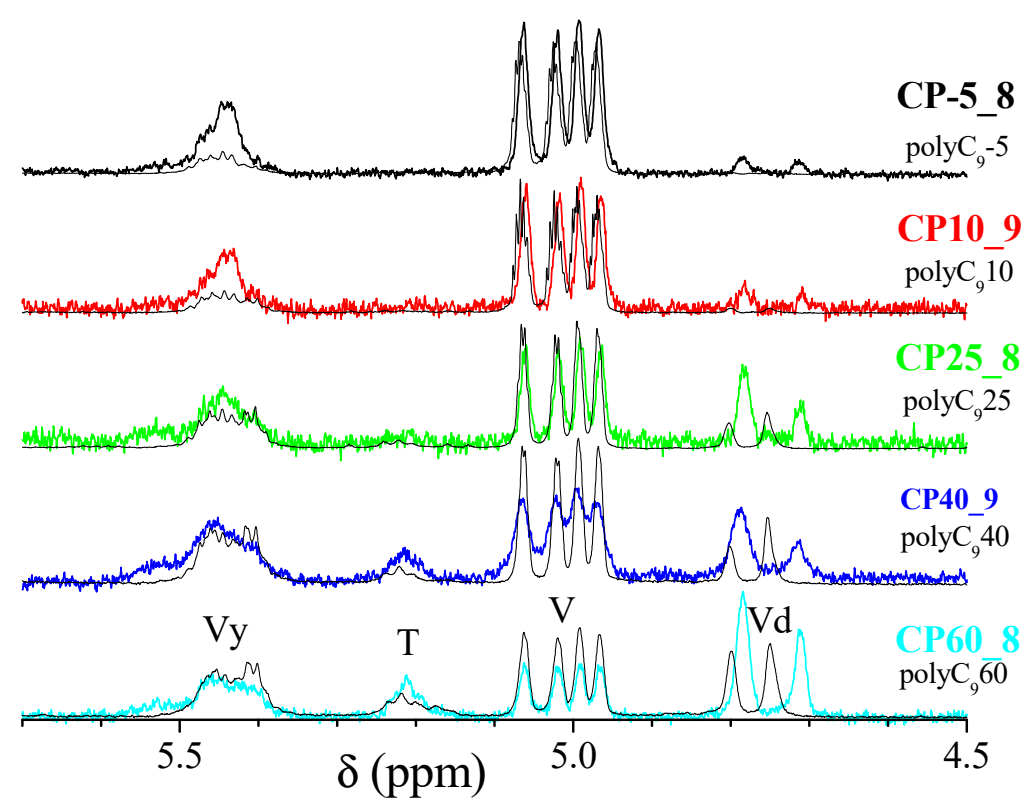

Figure 7. Olefinic window of ${ }^{1} \mathrm{H}$ NMR spectra for samples with comparable $\mathrm{C}_{9}$ contents, obtained at different $T_{\text {pol }}$. Spectra of corresponding polyC $C_{9}$ samples are shown for comparison.

As far as vinylidenes are concerned, the evolution with $C_{9}$ feeding fraction depends on $T_{\text {pol }}$ according to trends presented in the bottom plot of Figure 8. The relative magnitude of the reduction goes along with the selectivity found for the interaction of the catalyst towards $C_{9}$ comonomer, and it is increasingly pronounced as $T_{\text {pol }}$ decreases. The most important result is that these species come exclusively from propene units. It can be remarked, indeed, in Figure 7 that characteristic $V d$ signals of poly-1-nonene samples are completely absent in any copolymer. This specificity of the copolymer chain-growing termination has interesting mechanistic implications, which will be discussed later.

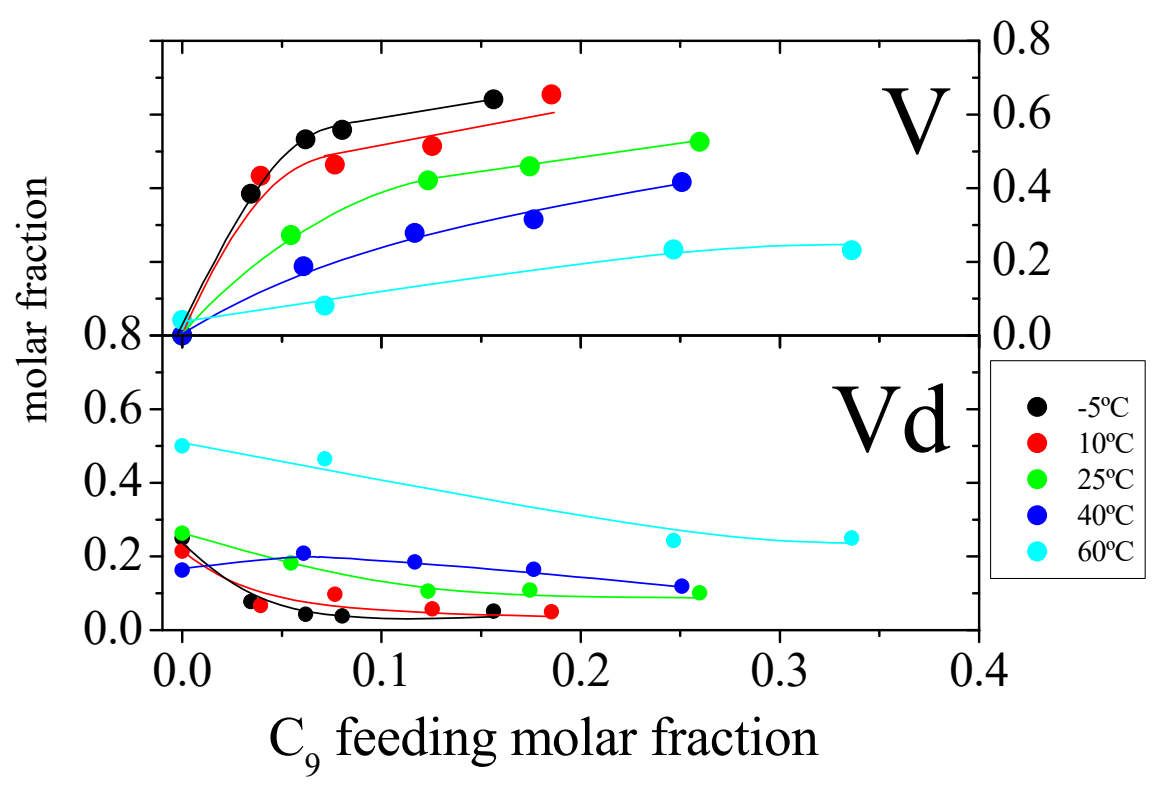

Figure 8. Evolution of $V d$ and $\mathrm{V}$ contents with the $\mathrm{C}_{9}$ feeding molar fraction for the different series. 
Comparisons made in Figure 7 between copolymers and their corresponding poly $\mathrm{C}_{9}$ samples really show that no $V d$ signals associated with $C_{9}$ units are present. Supporting this assertion, the ${ }^{1} \mathrm{H}_{-}{ }^{1} \mathrm{H}$ TOCSY spectrum of a copolymer (CPP60_12) shows correlation peaks between vinylidene signals and $V d$ methyl protons at 1.75 ppm (see in Figure 9).

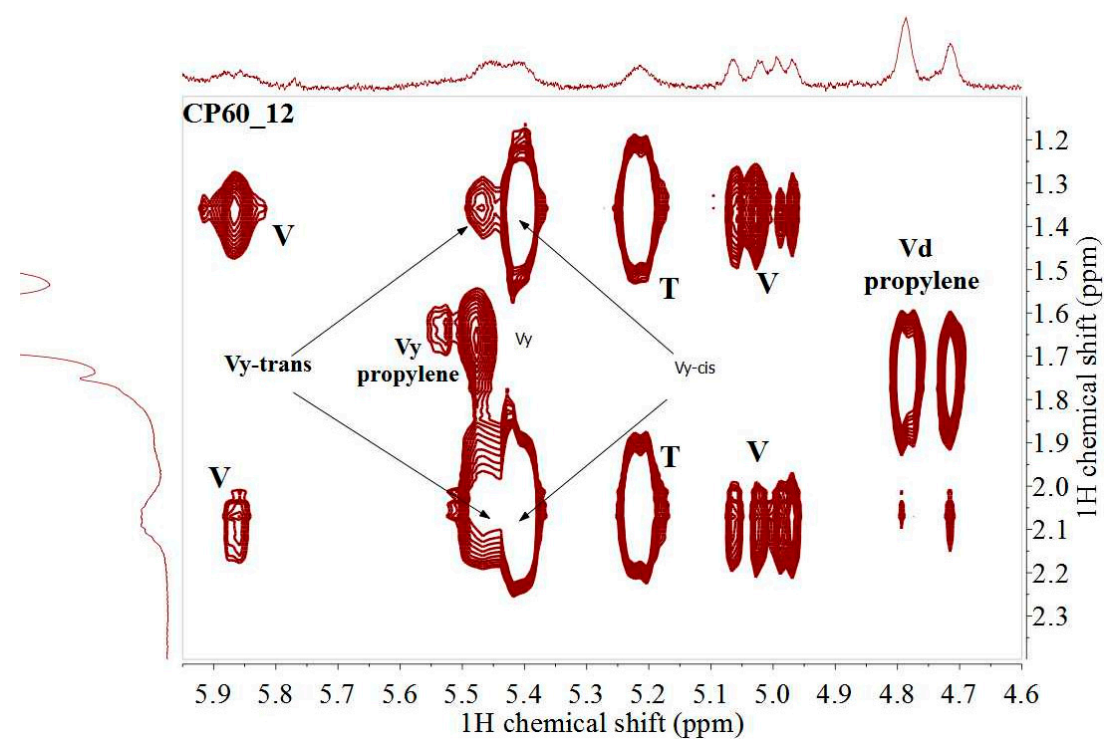

Figure 9. ${ }^{1} \mathrm{H}-{ }^{1} \mathrm{H}$ TOCSY map of the sample C9PP60_12.

Regarding vinyl chain-ends, they emerge according to trends shown in the upper plot of Figure 8, where it is quite noticeable that the progress is increasingly faster as $T_{\text {pol }}$ decreases, i.e., when the selectivity of the catalyst/comonomer interaction is improved and the stability of the propagating catalyst/growing chain complex is expected to increase.

Other emerging olefin species are vinylenes and trisubstituted olefins, of which their contents evolve with the $\mathrm{C}_{9}$ feeding, as depicted in Figure 10. While the former is present in all copolymer series, the latter is only found in copolymerizations at $40{ }^{\circ} \mathrm{C}$ upwards.

An inspection of ${ }^{1} \mathrm{H}$ NMR spectra of $\mathrm{PP}$ and poly-1-nonene samples proves that $V_{\mathrm{y}}$ are characteristic of both homopolymers (see for instance bottom and top spectra in Figure 2). Although characteristic ranges of $V_{\mathrm{y}}$ protons coming from propene and $\mathrm{C}_{9}$ overlap quite a lot, those ones belonging to propene insertions display a low-field component, which allows the distinguishing of their existence. Once again, comparison of both homopolymers in Figure 2 illustrates this fact. Additionally, the TOCSY spectrum of the C9PP60_12 in Figure 9 proves the existence of propene derived $V_{\mathrm{y}}$ groups, since the distinctive correlation signal with the methyl peak at $(5.54,1.64 \mathrm{ppm})$ is observed.

According to this assignment, the $V_{\mathrm{y}}$ trends shown in the bottom plot of Figure 10 are ascribed to the increasing impact of $V_{\mathrm{y}}$ associated with $\mathrm{C}_{9}$ units. This is an expected fact, which is accompanied by a significant qualitative change in the signal with $T_{\text {pol }}$. While a low-field multiplet is found in copolymers obtained at $-5,10$, and $25^{\circ} \mathrm{C}$, another additional high-field multiplet is detected in series 40 and 60 (see Figure 7). This change is not related to $C_{9}$ content, since the presence of one or two signals is preserved all along the range of the comonomer content studied at each series, and it must be connected to the temperature dependent production of one or two possible stereoisomers. The low-field signal is attributed to the trans configuration and the high-field component corresponds to the cis one $[64,67]$. 


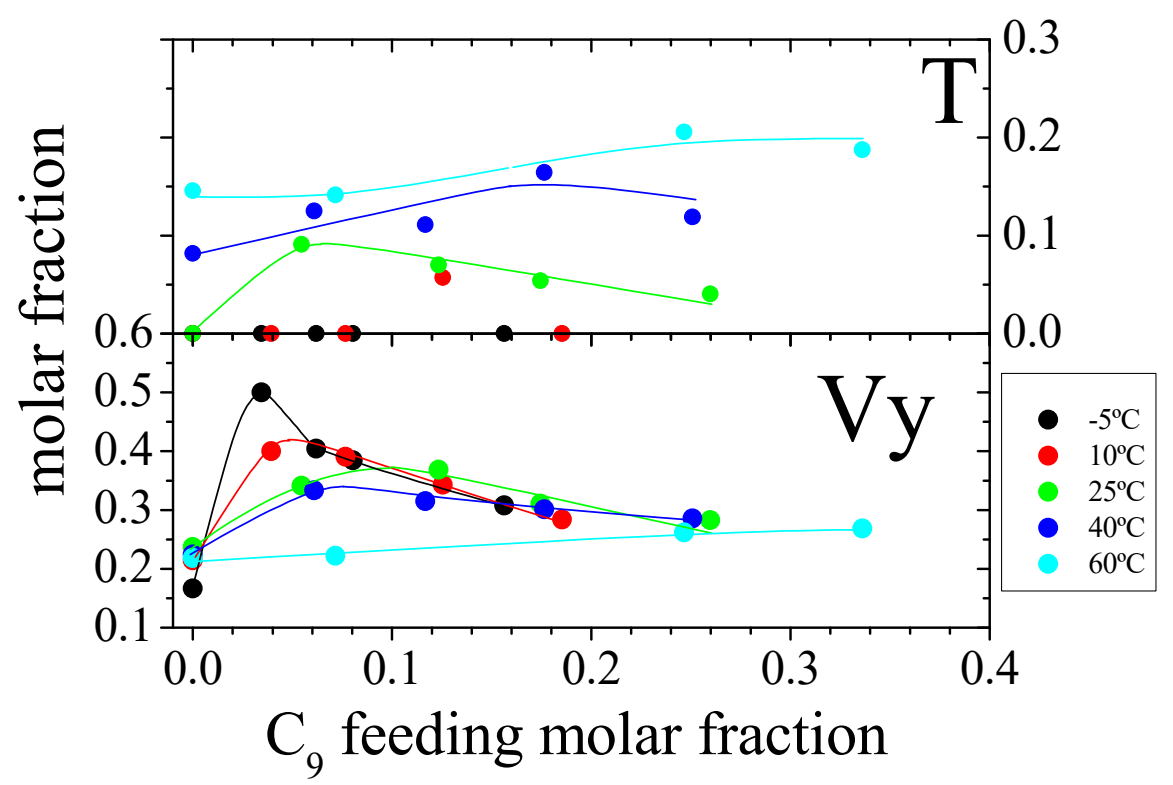

Figure 10. Evolution of $V_{\mathrm{y}}$ and $\mathrm{T}$ contents with the $\mathrm{C}_{9}$ feeding molar fraction for the different series.

Finally, trisubstituted olefins were detected at medium and high $T_{\text {pol }}$. As a matter of fact, the signal at $5.22 \mathrm{ppm}$ is exclusive of samples obtained from $25^{\circ} \mathrm{C}$ upwards in PP, poly-1-nonenes, or copolymers at any comonomer content.

The structure was found to be very simple, as displayed by a triplet centred at $5.22 \mathrm{ppm}$, based on the ${ }^{1} \mathrm{H}$ NMR spectra of PP and poly-1-nonene (bottom and top spectra in Figure 2, respectively). Such signal corresponds to the proton of a trisubstituted olefin contiguous to a methylene $[68,69]$. The TOCSY spectrum of the polyC ${ }_{9} 40$ (Figure 11) reveals correlation signals of the $T$ proton with methylene protons relatively placed in $\alpha$ and $\beta$, which are consistently assigned to such a structure.

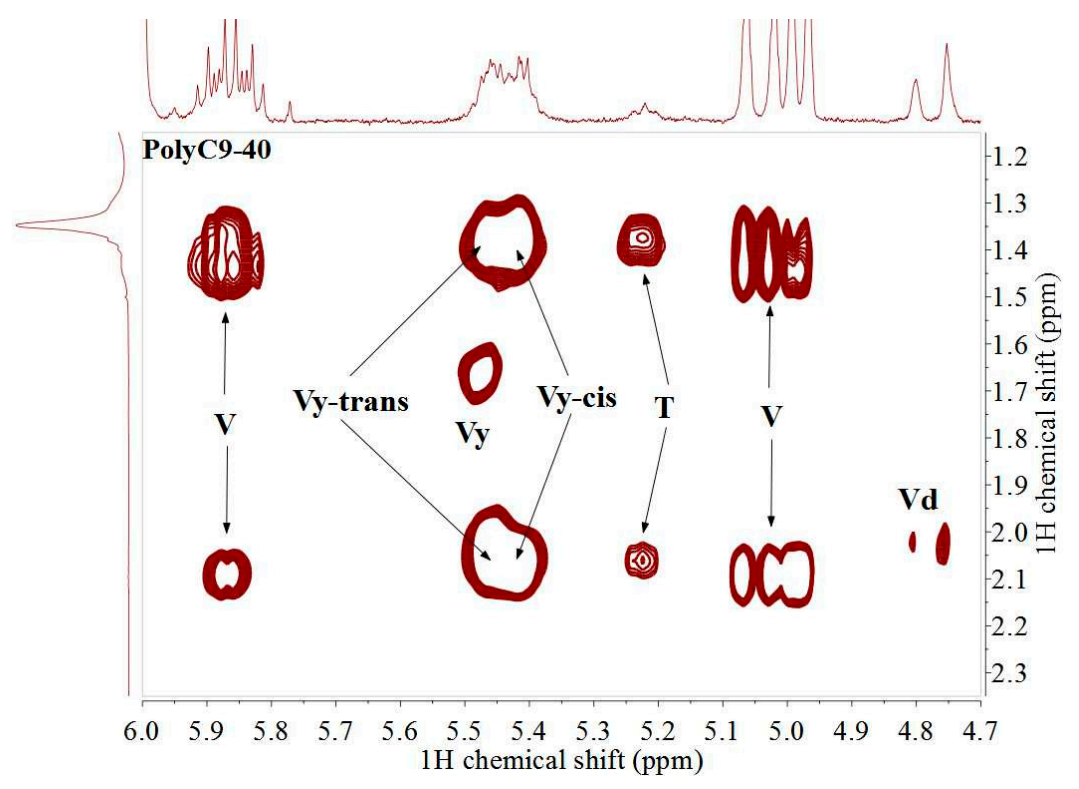

Figure 11. ${ }^{1} \mathrm{H}-{ }^{1} \mathrm{H}$ TOCSY map of the sample polyC $\mathrm{C}_{9} 40$.

The upper plot in Figure 10 displays the evolution of $T$ olefins with the $C_{9}$ feeding at the different $T_{\text {pol. }}$. The trends make evident that both $C_{9}$ content and temperature promote them and, in particular, that the content turn out to rise from zero up to a maximum at a low comonomer content for the $25^{\circ} \mathrm{C}$ series. This fact allows assuring that $T$ olefins are entirely associated with $\mathrm{C}_{9}$ insertions in this case. 
On the contrary, the presence of significant contents in PP40 and PP60 leads us to presume that these structures have their origin from both propene and $\mathrm{C}_{9}$ insertions. Regardless, the increment with comonomer content is indicative of the increasing engagement of $C_{9}$ units in $T$ production. In fact, the absence of the $T$ correlation signal with methyl protons in the 1.55-1.70 range (see TOCSY map in Figure 9) allows us to assure that most $T$ olefins are produced from 2,1 insertions of $C_{9}$.

\section{Discussion}

It is rather clear from Figure 4 that interaction of the catalyst site with $\mathrm{C}_{9}$ comonomer is increasingly favoured at low temperatures, i.e., under conditions promoting stable thermo-dynamic intermediates over those kinetically preferred. This fact has important consequences from a basic standpoint, since it reveals that such a kind of selectivity might play a considerable role in the catalyst's activity $[19,57]$ through changes in both initiation and termination of copolymerization.

Accordingly, the results of relative activities, shown in Figure 5, may be argued in similar terms. The raise in the relative activity and its shifting towards lower values of the $\mathrm{C}_{9}$ feeding molar fraction, when $T_{\text {pol }}$ diminishes, must be related to the above-mentioned selectivity of the catalyst towards $C_{9}$, rather than with the growing chain microstructure characteristics. As a matter of fact, the specific $\mathrm{C}_{9}$ content at which the maximum activity occurs differs from one set to another. $\mathrm{C}_{9}$ feeding fractions for the activity maxima do not correspond to similar $C_{9}$ contents into the copolymers, but to chain compositions increasingly richer in $\mathrm{C}_{9}$ as $T_{\text {pol }}$ rises up. Additionally, microstructure in tacticity was found to be quite different between the copolymer series. The tacticity distribution at the pentad level, shown in supplementary information (Table S1 in Supplementary Materials), displays that propene isotacticity decreases along with the rise in $T_{\text {pol }}$, contributing this way to enhance the solubility of chains. Therefore, it can be concluded that relative selectivity of the active centre itself on both comonomers is a factor fully involved in the enhanced kinetics of the copolymerization, more so than other factors promoting mass transfer, like enhanced chain solubility. Therefore, this result argues against the dependence of the catalyst activity on the degree of polymer chain bundling, since variation of relative activities is higher the lower the $T_{\text {pol }}$ used, just when the melting temperature increases (Table 1) and solubility of copolymers decreases.

Consequently, the selectivity of the catalyst-comonomer interaction must be a driving factor of the comonomer effect $[19,57]$. Firstly, the $\alpha$-olefin plays as a ligand of the metal centre and this interaction $[10,19]$, which is favoured at lower temperatures, might assist the separation of the ionic pair promoting an enhancement of the propagation rate. Secondly, and more importantly, the content of initiating sites available is expected to increase due to the role of the 1-nonene in the chain termination. This fact would be conclusive if a triggering effect of the comonomer in the chain initiation $[4,12,44]$ is accepted. Indeed, the evolution of molecular weights, presented in Figure 6, provides strong evidence about the implication of 1-nonene in chain termination. The temperature dependence of the molecular weight goes along with the described variation of the catalyst specificity when interacting with $C_{9}$. The analysis of chain-end groups, shown next, will allow the confirmation that $C_{9}$ insertions are directly responsible for the termination processes and, thereby, for the recovery of chain-free active sites.

The following discussion will be carried out on the assumption that termination mechanisms leading to chain-end olefins mainly involve transfer processes to the catalyst from the $\beta$ position into the last inserted unit of growing chains. This ensemble of reactions has proven to successfully explain the presence of olefin species found in the copolymers under study [57,64,68,70-78]. Additionally, allylic activation of chain-end olefin species will also be considered in order to account for the formation of in-chain double bonds. The structures of chain-end groups are collected in Schemes 3 and 4 . The former displays the olefin species resulting from $\beta-\mathrm{H}$ transfer processes and the latter displays those coming from $\beta$-alkyl transfers. Steric considerations lead to the exclusion of any possibility of insertion after the regio-irregular incorporation of either comonomers (routes B). Subsequent $\beta$-transfer steps would yield olefin structures that are not observed. The only exception is the well-known regular 1,2-propene 
addition after an irregular propene insertion, which produces mid-chain regiodefects detected in PP homopolymers and low $\mathrm{C}_{9}$ content copolymers.

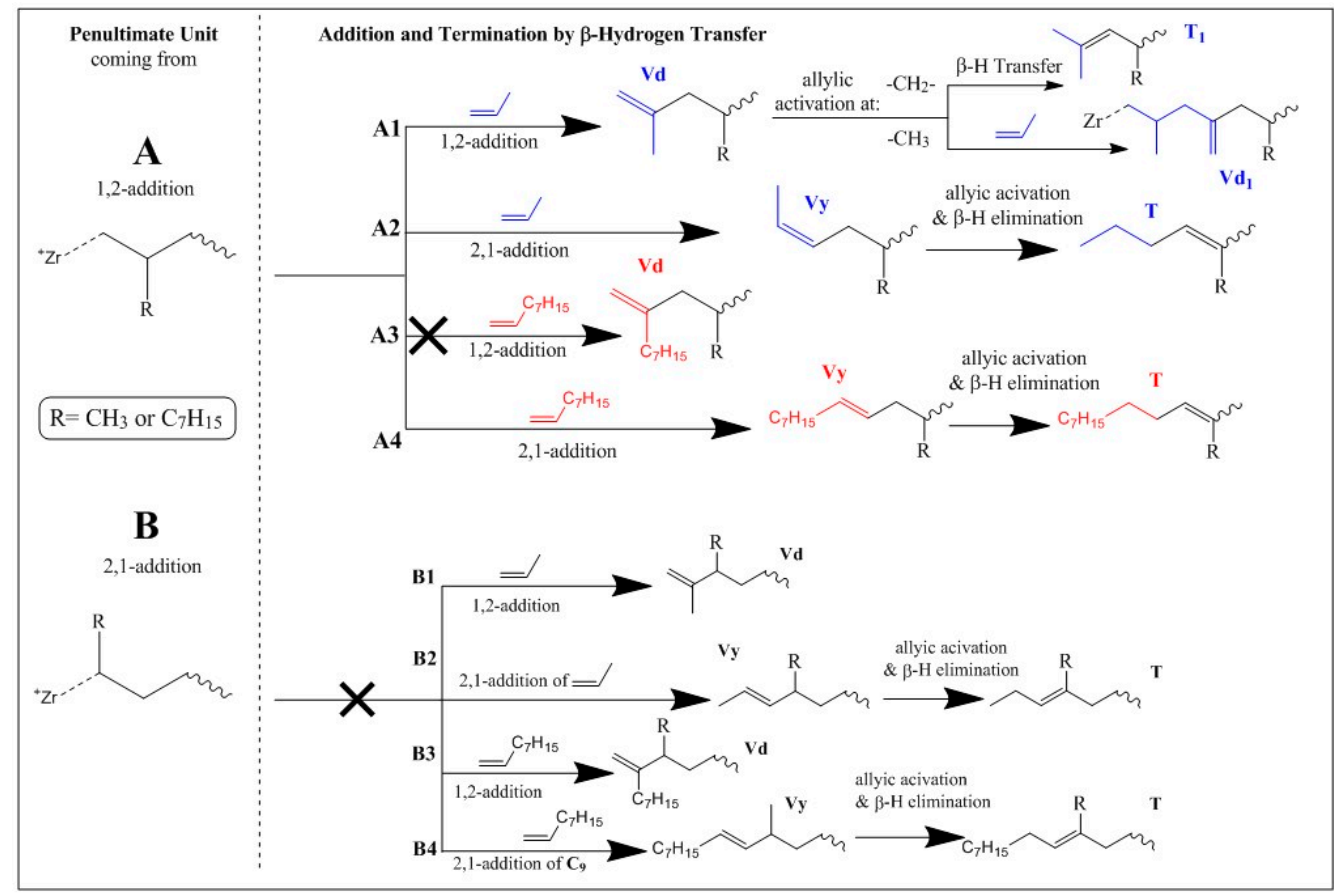

Scheme 3. Termination routes (A and $\mathbf{B})$ through the $\beta$-Hydrogen transfer processes.

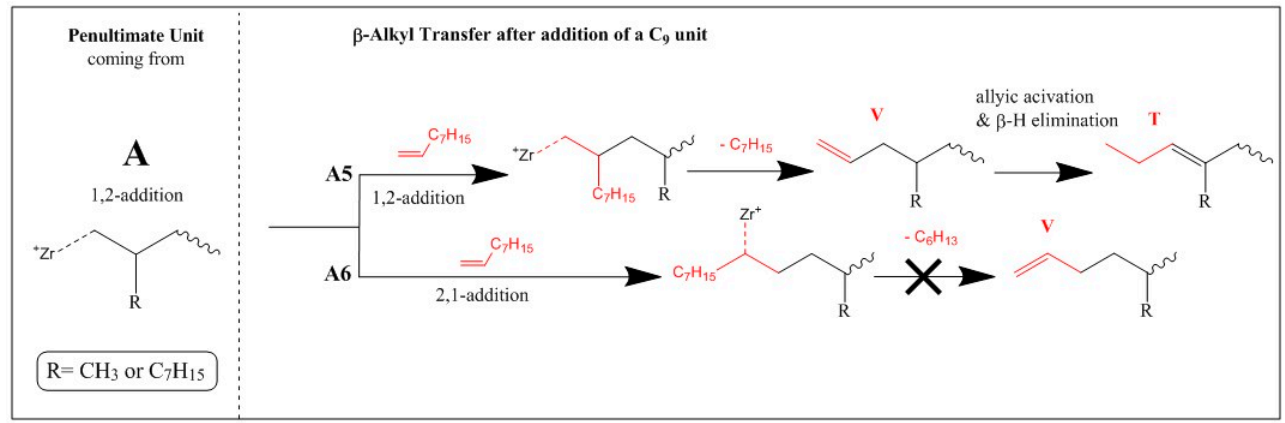

Scheme 4. Termination route (A) through $\beta$-alkyl transfer processes from $C_{9}$ end units.

Vinylidenes $(V d)$. The most important fact concerning the nature of these species is that $V d$ are exclusively caused by $\beta-\mathrm{H}$ transfers from regio-regular propene terminated chains (Scheme 3, route A1) because route $\mathrm{A} 3$ is forbidden. Absence of $V d$, arising from regio-regular $\mathrm{C}_{9}$ co-units, is surprising if it is considered that this process is an effective termination mechanism in $C_{9}$ homopolymerization.

The main alternative to this selective blocking towards the capture of the $\beta$-placed hydrogen in 1,2-inserted $C_{9}$ units by the catalyst seems not to be propagation, but $\beta$-alkyl transfer, which will be discussed below. Whatever the reason might be, it is quite evident that the hindrance of a $C_{7}$ long side branch itself is not the primary cause, since such a termination mechanism is not forbidden in poly-1-nonenes. The fact that $T_{\text {pol }}$ is essential for the production of $V d$ chain-ends in some of the poly-1-nonenes (see the vanishing of $V d$ signals in poly $C_{9}$ spectra in Figure 7 when $T_{\text {pol }}$ is reduced), this suggests that more stable conformations in the catalyst-last linked unit structure are far from enabling short-range interactions between the metal centre and the hydrogen $\beta$-placed. A requirement that is necessary for the $\mathrm{H}$-transfer to take place is through either a bimolecular or a unimolecular pathway [64]. 
Although the influence of $T_{\text {pol }}$ on the feasibility of the $\beta-\mathrm{H}$ transfer is clear, it is indeed the conformational mobility of the chain that seems to be the true driving factor. This is supported by the unequivocal involvement of chain composition. Actually, it is apparent that rather rigid propene-rich chains in the C9PP60 series do not show any trace of $\mathrm{C}_{9}$-associated $V d$ groups, as would otherwise have been expected at $60^{\circ} \mathrm{C}$. It is then plausible that a minimum $\mathrm{C}_{9}$ content exists that is able to confer enough chain mobility to allow $\beta-H$ transfers in regularly inserted $C_{9}$ units.

There is a particular type of $V d$ olefin that is mostly located inside chains $\left(V d_{1}\right)$, as commented in the results section. These olefins are detected in both PP and copolymers and are exhibited by the increased intensity of the $4.79 \mathrm{ppm}$ peak over the $4.71 \mathrm{ppm}$ one $[64-66,69,78]$. These groups are directly associated with propene units and their presence has been justified by resorting to allylic re-activation of the $V d$ methyls (Scheme 3, pathway A1). This is a process that enters into competition with allylic activation of $V d$ methylene groups (also shown in Scheme 3, pathway A1), which renders the special trisubstituted olefin $\left(T_{1}\right)$. Nevertheless, the presence of $C_{9}$ co-units greatly reduces the occurrence of $V d_{1}$ at any temperature. This is visually shown in Figure 12. In the specific case of PP samples, the variation of the relative content of $V d_{1}$ with $T_{\text {pol }}$ displays the trend depicted in the insert of Figure 12. These groups decrease markedly at high temperatures, although its content seems to grow a little from -5 to $25^{\circ} \mathrm{C}$.

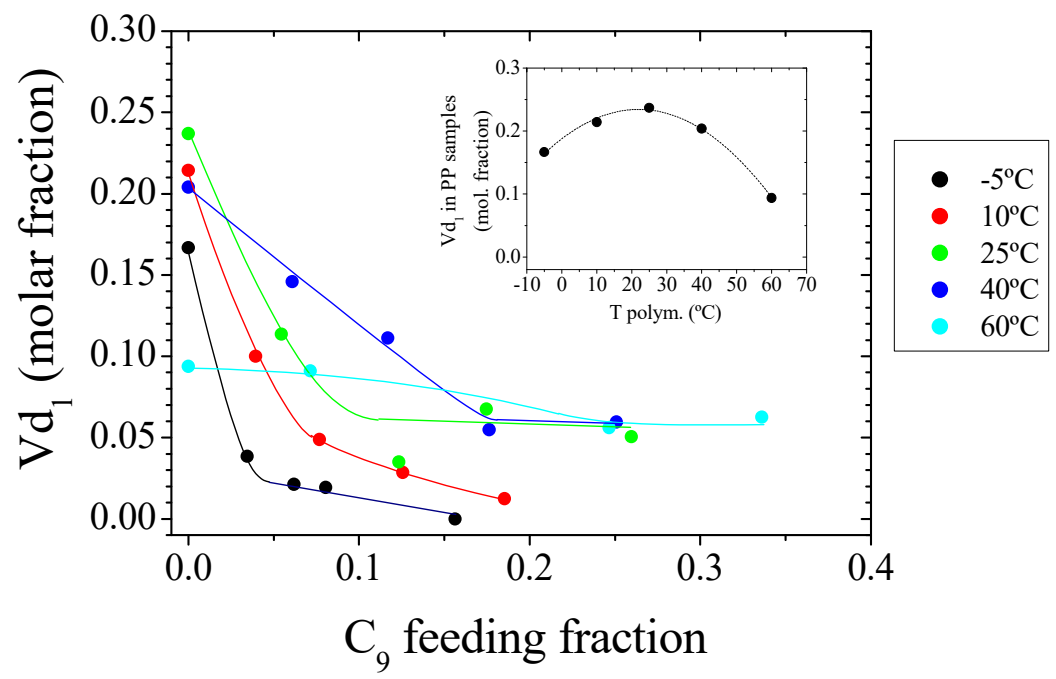

Figure 12. Evolution of $V d_{1}$ content with the $C_{9}$ feeding molar fraction for the different series.

Vinyls $(V)$. These chain-end olefins must come from $\beta$-alkyl transfers of the seven carbon length side branch in 1,2-inserted $C_{9}$ units. Scheme 4 shows the range of possibilities in the generation of vinyls from regular insertion of $C_{9}$ units. Among the options displayed, $\beta$-alkyl transfer is thought to be restricted to specific 1,2-inserted $C_{9}$ units (route A5), since coordination states following 2,1-insertions of $\mathrm{C}_{9}$ have very accessible $\mathrm{H}$ atoms on both side $\beta$ positions, which are available to be captured by the metal centre (route A6). Consequently, 2,1-inserted $C_{9}$ units will evolve to vinylene functionalities, as shown in route A4 of Scheme 3.

When the selectivity of the catalyst/comonomer interaction is improved and the stability of the propagating catalyst/growing chain complex increases, i.e., at low $T_{\text {pol }}$ values, then $\beta$-alkyl transfers are facilitated. The fact is that $\beta-\mathrm{H}$ transfer is absolutely blocked under any of the polymerization conditions used and the $\beta$-alkyl transfer becomes the only way out to finish propagation from 1,2-inserted $C_{9}$ units, with the only option of further evolving to trisubstituted olefins (Scheme 4, route A5). This eventuality is disabled at -5 and $10^{\circ} \mathrm{C}$, as will be discussed below. To the best of our knowledge, the prevalence of such a termination mechanism in copolymerization is a novel result in $\alpha$-olefin copolymerization.

As aforementioned in the discussion on vinylidenes, the selectivity of 1,2-inserted $C_{9}$ units towards $\beta$-alkyl transfer is barely altered at $60{ }^{\circ} \mathrm{C}$ and for a $\mathrm{C}_{9}$ content of $12 \mathrm{~mol} \%$, despite the fact that $\beta-\mathrm{H}$ 
transfer in 1,2-inserted $C_{9}$ shows up as an active mechanism in $C_{9}$ homopolymerization. It is then clear that, even though $T_{\text {pol }}$ is a factor to take into account the production of $V d$ associated with $C_{9}$ units, the absence of these species in these copolymer samples results in suspicion that the composition of the growing chain has a significant role in the competition between both $\beta$ transfer processes. This is an issue that is worth studying by widening the range of comonomer content.

Vinylenes $\left(V_{\mathrm{y}}\right)$. It is assumed that these olefins have their origin in 2,1-insertions, whatever the unit inserted is, either propene [64,68,77,79] or $\alpha$-olefin [70-72], and their formation can consistently be accounted for by routes A2 and A4 in Scheme 3.

According to the assignment detailed in the results section, it is evident that unimolecular $\beta-\mathrm{H}$ transfers in 2,1-inserted $C_{9}$ units are the sole process when $T_{\text {pol }}$ is $-5,10$, and $25^{\circ} \mathrm{C}$, since only trans $V_{\text {y }}$ groups are detected. However, at 40 and $60^{\circ} \mathrm{C}$, the copolymers also exhibit the high-field component, ascribed to the cis configuration, which must be related to the concurrence of bimolecular $\beta-\mathrm{H}$ transfers [64,67].

It is worth mentioning that when the $\mathrm{C}_{9}$ presence in the reaction medium rises up, the content of $V_{\text {y }}$ apparently decreases in the series at -5 and $10{ }^{\circ} \mathrm{C}$ (Figure 10 down). This can be ascribed to a lesser impact of $\mathrm{C}_{9}$ 2,1-misinsertions since, as will be discussed in the next point, no further evolution of $V_{\mathrm{y}}$ to $\mathrm{T}$ species takes place at these temperatures. On the contrary, from $25^{\circ} \mathrm{C}$ upwards, isomerization of $V_{\mathrm{y}}$ groups to $\mathrm{T}$ ones occurs to some extent. In these cases, the joint evolution of both olefins in copolymer samples shows little variation with the $\mathrm{C}_{9}$ content. Furthermore, no significant trend differences are found between them (see Graph S1 in Supplementary Materials).

Trisubstituted olefins $(T)$. These species are thought to come from allylic activation of $V_{\mathrm{y}}$ groups [64,68-70]. The mechanism proposed in literature to account for T olefins is based on the fact that trisusbstituted and $V_{\mathrm{y}}$ species are found together in PP $[64,68,70]$. It assumes that allylic activation of $V_{\mathrm{y}}$ groups is the route leading to $T$ olefins (pathways A2 and A4 in Scheme 3 and A5 Scheme 4). This mechanism seemingly plays a more active role when $T_{\text {pol }}$ increases.

Isobutyl ones $\left(T_{1}\right)$ are a particular group within these chain-end olefins. These species are exclusively present in PP samples and they have been proposed to come from the isomerisation of $V d$ groups, via allylic activation through the interaction with the catalyst centre (Scheme 3, pathway A1) $[64,68,69,78-80]$. There is absolutely no evidence of this group in copolymers and further, the possibility of generating $T_{1}$ via pathway $\mathrm{A} 1$ is ruled out in these samples. This fact additionally assures that such an isomerisation route does not occur as a consequence of the high temperature used in NMR characterisation, but because of termination mechanisms.

The relative content of $T_{1}$ in PP samples is found to decrease with $T_{\mathrm{pol}}$, following the trend shown in Figure 13. Such an evolution can be reasonably explained in terms of the ability of the catalyst centre to interact back with the vinylidene, an eventuality that is expected to be promoted at low temperatures when rather slow termination kinetics favour the interaction between the catalyst and the closest olefin $V d$ group.

It is, therefore, apparent that termination events associated with $C_{9}$ insertions are directly responsible for the molecular weight reduction found and, hence, for the recovery of free-chain catalyst centres. The mechanistic considerations performed allow the identification of which termination routes lay behind the chain termination ability of inserted $C_{9}$ units. While regio-irregular insertions necessarily lead to $\beta-\mathrm{H}$ transfer, regio-regular ones show a high propensity to finish chain propagation through $\beta$-alkyl type. The former produces vinylene chain-ends and the latter, vinyls. Such processes are in fact the main source of free-chain active sites during copolymerization, of which their involvement in the triggering action of the $\alpha$-olefin has been suggested as the origin of the "comonomer effect" [44]. This work's results point to that possibility, however the way that it would occur is open to discussion, because the specificity of the metallocene catalysis may require the trigger mechanism, proposed by Ystenes [12] for Ziegler-Natta catalysts, to be adapted. In fact, the solvation effect reviewed by Kryzhanovskii [19] might serve as the $\alpha$-olefin assisted mechanism to explain rate enhancement. 


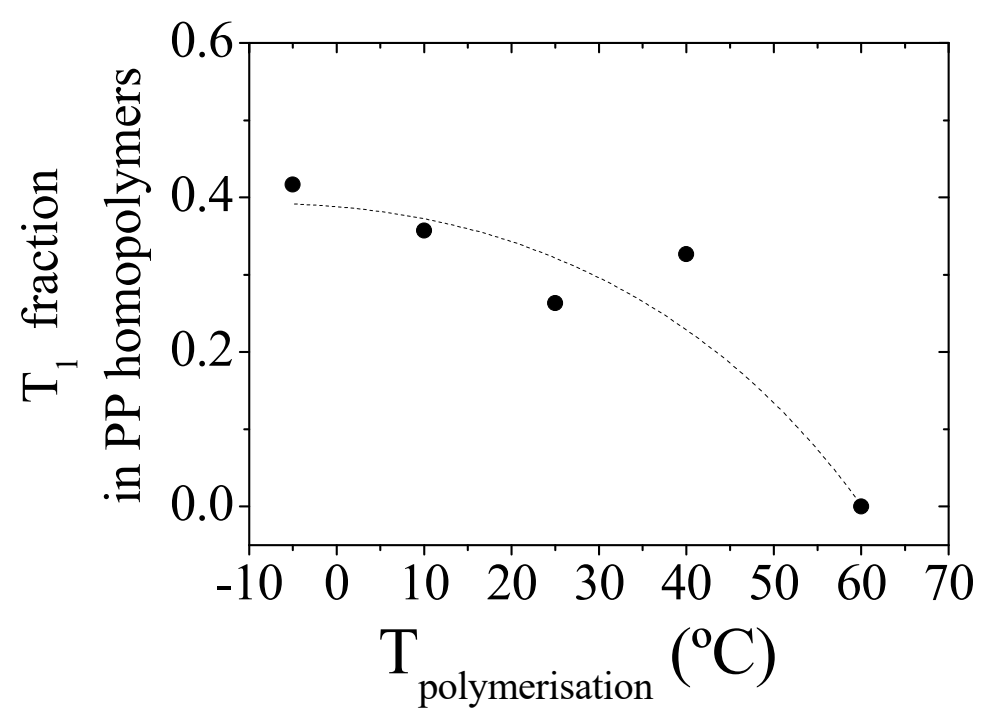

Figure 13. Evolution of $T_{1}$ content in PP samples with $T_{\text {pol }}$.

It has been proposed that comonomer molecules themselves play a role as transfer agents, causing molecular weight decrease [7]. Although this possibility of producing chain-free catalyst sites exists, this work shows how fresh initiating sites mostly come from the very chain releasing mechanisms associated with $C_{9}$ insertions, even without the engagement of any other molecule. In fact, $\beta$-alkyl transfer is probably unimolecular $[81,82]$ and $\beta-\mathrm{H}$ transfer at -5 and 10 in $2,1-\mathrm{C}_{9}$ insertions are also entirely unimolecular, as can be deduced from the exclusive formation of trans- $V_{\mathrm{y}}$ olefins $[64,67]$.

\section{Conclusions}

The metallocene copolymerization of propene and 1-nonene is a temperature dependent process. The selectivity of the catalyst towards the $\alpha$-olefin is, in fact, higher as the polymerization temperature is lowered. This fact seems to lay at the core of the activity increase undergone by the catalyst, just by adding small fractions of 1-nonene. Accordingly, the relative activity increment turns out to be proportional to the selectivity for the 1-nonene insertion.

The $\alpha$-olefin promotes the termination of propagation by means of chain transfer mechanisms, from both regio-regular and regio-irregular insertion modes. As a matter of fact, although 1,2-insertions of $\mathrm{C}_{9}$ do not necessarily yield chain termination, the $\beta$-alkyl transfer process is specially preferred and vinyl chain-ends derived from this mechanism are predominant all along the conversion range studied. Concurrently with this termination pathway, regio-irregular 2,1-insertions also contribute significantly, since its occurrence stops chain growth by forcing $\beta$-Hydrogen transfer to take place. In this case, the resulting chain-end olefins are vinylidene type.

The detailed transfer processes furnish chain-free active sites, which have been suggested to be involved in especially promoted insertions, mediated by the $\alpha$-olefin's triggering role. These results agree with some recent findings on Phillip catalysis and open up a new insight into the comprehension of the comonomer effect in metallocene copolymerization.

Finally, it is worth highlighting that the absolute prevalence of $\beta$-alkyl transfer over $\beta$-Hydrogen one in 1,2-inserted $C_{9}$ units is a non-reported selective termination mechanism, of which its underlying reasons must still be addressed. The fact that both termination events take place in $\mathrm{C}_{9}$ homopolymerization in a relative proportion that depends on $T_{\text {pol }}$ suggests that competence between the two processes is likely governed by chain mobility.

Supplementary Materials: The following are available online at http://www.mdpi.com/2073-4360/11/8/1266/s1, Table S1: Relative content of pentads and regiodefects (in mol \%) and average isotactic length $\left(n_{1}\right)$, Graph S1: Joint evolution of $V_{\mathrm{y}}$ and $T$ olefins with the $\mathrm{C}_{9}$ feeding molar fraction. 
Author Contributions: Conceptualization, J.M.G.-E.; methodology, J.M.G.-E.; validation, M.L.C., R.B., E.P., and J.M.G.-E.; formal analysis, Q.W., A.G.-P., R.B., E.P., and J.M.G.-E.; investigation, Q.W., A.G.-P., R.B.-G., M.L.C., R.B., E.P., and J.M.G.-E.; resources, Q.W., A.G.-P., R.B.-G., M.L.C., R.B., E.P., and J.M.G.-E.; data curation, Q.W., A.G.-P., R.B., E.P., and J.M.G.-E.; writing—original draft preparation, J.M.G.-E.; writing—review and editing, M.L.C., R.B., E.P., and J.M.G.-E.; visualization, M.L.C., R.B., E.P., and J.M.G.-E.; supervision, J.M.G.-E.; project administration, M.L.C., R.B., E.P., and J.M.G.-E.; funding acquisition, M.L.C., E.P., R.B., and J.M.G.-E.

Funding: This research was funded by the Agencia Estatal de Investigacion (AEI, Spain), together with the European Regional Development Fund (FEDER, UE), grant number MAT2016-79869-C2-1-P. Human resources funding was provided by the Hong Kong University of Science and Technology, in the frame of the CSIC-HKUST cooperation, grant number HKUST2017-25, and by the Ministerio de Economía y Competitividad (MINECO, Spain), grant number BES-2014-070972.

Acknowledgments: Q.W. thanks the HKUST and the CSIC for the Master student funding (HKUST2017-25). R.B.-G. also thanks the Ministerio de Economía y Competitividad (MINECO, Spain) for the predoctoral funding (BES-2014-070972).

Conflicts of Interest: The authors declare no conflict of interest. The funders had no role in the design of the study; in the collection, analyses, or interpretation of the data; in the writing of the manuscript, or in the decision to publish the results.

\section{References}

1. Chien, J.C.W.; Nozaki, T. Ethylene-hexene copolymerization by heterogeneous and homogeneous Ziegler-Natta catalysts and the "comonomer" effect. J. Polym. Sci. A 1993, 31, 227-237. [CrossRef]

2. Herfert, N.; Montag, P.; Fink, G. Elementary processes of the Ziegler catalysis, 7 a). Ethylene, $\alpha$-olefin and norbornene copolymerization with the stereorigid catalyst systems $\mathrm{Pr}[\mathrm{FluCp}] \mathrm{ZrCl}_{2} / \mathrm{MAO}$ and $\mathrm{Me}_{2} \mathrm{Si}[\mathrm{Ind}]_{2} \mathrm{ZrCl}_{2} / \mathrm{MAO}$. Macromol. Chem. Phys. 1993, 194, 3167-3182. [CrossRef]

3. Nedorezova, P.M.; Chapurina, A.V.; Koval'chuk, A.A.; Klyamkina, A.N.; Aladyshev, A.M.; Optov, V.A.; Shklyaruk, B.F. Copolymerization of propylene with 1-octene initiated by highly efficient isospecific metallocene catalytic systems. Polym. Sci. Ser. B 2010, 52, 15-25. [CrossRef]

4. McDaniel, M.P.; Schwerdtfeger, E.D.; Jensen, M.D. The comonomer effect on chromium polymerization catalysts. J. Catal. 2014, 314, 109-116. [CrossRef]

5. Tait, P.J.; Downs, G.W.; Akimbami, A.A. Copolymerization of ethylene and $\alpha$-olefins: A kinetic consideration. In Transition Metal Catalyzed Polymerizations Ziegler-Natta and Metathesis Polymerizations; Quirk, R.P., Ed.; Cambridge University Press: Cambridge, UK, 1988; pp. 834-860.

6. Uozumi, T.; Soga, K. Copolymerization of olefins with Kaminsky-Sinn-type catalysts. Macromol. Chem. Phys. 1992, 193, 823-831. [CrossRef]

7. Koivumäki, J.; Seppälä, J.V. Observations on the rate enhancement effect with $\mathrm{MgCl}_{2} / \mathrm{TiCl}_{4}$ and $\mathrm{Cp}_{2} \mathrm{ZrCl}_{2}$ catalyst systems upon 1-hexene addition. Macromolecules 1993, 26, 5535-5538. [CrossRef]

8. Koivumäki, J.; Fink, G.; Seppälä, J.V. Copolymerization of ethene/1-dodecene and ethene/ 1-octadecene with the stereorigid zirconium catalyst systems $\mathrm{iPr}[\mathrm{FluCp}] \mathrm{ZrCl}_{2} / \mathrm{MAO}$ and $\mathrm{Me}_{2} \mathrm{Si}[\mathrm{lnd}]_{2} \mathrm{ZrCl}_{2} / \mathrm{MAO}$ : Influence of the comonomer chain length. Macromolecules 1994, 27, 6254-6258. [CrossRef]

9. Koivumäki, J.; Seppälä, J.V.; Liu, X. Co- and terpolymerization of ethylene with 1-butene and 1-decene by using $\mathrm{Cp}_{2} \mathrm{ZrCl}_{2}$-methylaluminoxane catalyst. J. Polym. Sci. A 1993, 31, 3447-3452. [CrossRef]

10. Karol, F.J.; Kao, S.C.; Cann, K.J. Comonomer effects with high-activity titanium and vanadium-based catalysts for ethylene polymerization. J. Polym. Sci. A 1993, 31, 2541-2553. [CrossRef]

11. Tsutsui, T.; Kashiwa, N. Kinetic study on ethylene polymerization with $\mathrm{Cp}_{2} \mathrm{ZrCl}_{2} / \mathrm{Methylaluminoxane}$ catalyst system. Polym. Commun. 1998, 29, 180-183.

12. Ystenes, M. The trigger mechanism for polymerization of $\alpha$-olefins with Ziegler-Natta catalysts: A new model based on interaction of two monomers at the transition state and monomer activation of the catalytic centres. J. Catal. 1991, 129, 383-401. [CrossRef]

13. Valvassori, A.; Sartori, G.; Mazzanti, G.; Pazaro, G. Kinetics of the ethylene-propylene copolymerization. Macromol. Chem. Phys. 1963, 61, 46-62. [CrossRef]

14. Finogenova, L.T.; Zakharov, V.A.; Bunyiat-Zade, A.A.; Bukatov, G.D.; Plaksunov, T.K. Study of copolymerization of ethylene with hex-1-ene on applied catalysts. Polym. Sci. USSR 1980, 22, 448-454. [CrossRef] 
15. Calabro, D.C.; Lo, F.Y. A comparison of the reaction kinetics for the homo and copolymerization of ethylene and hexene with a heterogeneous catalyst. In Transition Metal Catalyzed Polymerizations Ziegler-Natta and Metathesis Polymerizations; Quirk, R.P., Ed.; Cambridge University Press: Cambridge, UK, 1988; pp. 729-739.

16. Ray, W.H. Practical benefits from olefin polymerization reactions. In Transition Metal Catalyzed Polymerizations Ziegler-Natta and Metathesis Polymerizations; Quirk, R.P., Ed.; Cambridge University Press: Cambridge, UK, 1988; pp. 563-590.

17. Bukatov, G.D.; Yeckevskaya, L.G.; Zakharov, V.A. Copolymerization of ethylene with $\alpha$-olefins by highly active supported catalysts of various composition. In Transition Metals and Organometallics as Catalysts for Olefin Polymerization; Kaminsky, W., Sinn, H., Eds.; Springer: Berlin, Germany, 1988; pp. 101-108.

18. Lin, S.; Wang, H.; Zhang, Q.; Lu, Z.; Lu, Y. Ethylene polymerization with modified supported catalysts. In Catalytic Polymerization of Olefins; Keii, T., Soga, K., Eds.; Elsevier: New York, NY, USA, 1986; pp. 91-107.

19. Kryzhanovskii, A.V.; Ivanchev, S.S. Synthesis of linear polyethylene on supported Ziegler-Natta catalysts. Review. Polym. Sci. USSR 1990, 32, 1312-1329. [CrossRef]

20. Spitz, R.; Duranel, L.; Masson, P.; Darricades-Llauro, M.F.; Guyot, A. Difference in reactivity between ethylene and propene with supported Ziegler-Natta catalysts. In Transition Metal Catalyzed Polymerizations Ziegler-Natta and Metathesis Polymerizations; Quirk, R.P., Ed.; Cambridge University Press: Cambridge, UK, 1988; pp. 719-728.

21. Tait, P.J.T. Newer aspects of active centre determination in Ziegler-Natta polymerization using ${ }^{14} \mathrm{CO}$ radio-tagging. In Transition Metals and Organometallics as Catalysts for Olefin Polymerization; Kaminsky, W., Sinn, H., Eds.; Springer: Berlin, Germany, 1988; pp. 309-327.

22. Gul'tseva, N.M.; Ushakova, A.M.; Aladyshev, A.M.; Rasporov, L.N.; Meshkova, I.N. Influence of the monomer nature on the activity of the supported titanium catalyst of polymerization of $\alpha$-olefins. Polym. Sci. 1991, 33, 987-993. [CrossRef]

23. Wester, T.S.; Ystenes, M. Kinetic studies of the injection of comonomers during polymerization of ethene and propene with $\mathrm{MgCl}_{2}$-supported Ziegler-Natta catalysts. Macromol. Chem. Phys. 1997, 198, 1623-1647. [CrossRef]

24. Jaber, I.A.; Ray, W.H. Polymerization of olefins through heterogeneous catalysis. XIII. The influence of comonomer in the solution copolymerization of ethylene. J. Appl. Polym. 1993, 49, 1709-1724. [CrossRef]

25. Koivumäki, J.; Seppälä, J.V. Observations on the synergistic effect of adding 1-butene to systems polymerized with $\mathrm{MgCl}_{2} / \mathrm{TiCl}_{4}$ and $\mathrm{Cp}_{2} \mathrm{ZrCl}_{2}$ Catalysts. Macromolecules 1994, 27, 2008-2012. [CrossRef]

26. Gul'tseva, N.M.; Ushakova, A.M.; Aladyshev, A.M.; Rasporov, L.N.; Meshkova, I.N. Influence of the nature of monomers on the activity of supported titanium catalysts in the $\alpha$-olefin polymerization. Polym. Bull. 1992, 29, 639-646. [CrossRef]

27. Kravchenko, R.; Waymouth, R.M. Ethylene-propylene copolymerization with 2-Arylindene zirconocenes. Macromolecules 1998, 31, 1-6. [CrossRef]

28. Kaminsky, W.; Kulper, K.; Nieboda, S. Olefin polymerization with highly active soluble zirconium compounds using aluminoxane as co-catalyst. Macromol. Symp. 1986, 3, 377-387. [CrossRef]

29. Cruz, V.L.; Muñoz-Escalona, A.; Martinez-Salazar, J. A theoretical study of the comonomer effect in the ethylene polymerization with zirconocene catalytic systems. J. Polym. Sci. A 1998, 36, 1157-1167. [CrossRef]

30. Meshkova, I.N.; Ushakova, T.M.; Gul'tseva, N.M.; Grinev, V.G.; Ladygina, T.A.; Novokshonova, L.A. Modification of polyolefins as a modern strategy to designing polyolefin materials with a new complex of properties. Polym. Sci. Ser. A 2008, 50, 1161-1174. [CrossRef]

31. Jungling, S.; Koltzenburg, S.; Multhaupt, R. Propene homo- and copolymerization using homogeneous and supported metallocene catalysts based on $\mathrm{Me}_{2} \mathrm{Si}(2-\mathrm{Me}-\mathrm{Benz}[\mathrm{e}] \mathrm{Ind}){ }_{2} \mathrm{ZrCl}_{2}$. J. Polym. Sci. A 1997, 35, 1-8. [CrossRef]

32. Awudza, J.A.M.; Tait, P.J.T. The "Comonomer effect" in ethylene/ $\alpha$-olefin copolymerization using homogeneous and silica-supported $\mathrm{Cp}_{2} \mathrm{ZrCl}_{2} / \mathrm{MAO}$ catalyst systems: Some insights from the kinetics of polymerization, active centre studies and polymerization temperature. J. Polym. Sci. A 2008, 46, 267-277. [CrossRef]

33. Coates, G.W.; Hustad, P.D.; Reinartz, S. Catalysts for the living insertion polymerization of alkenes: Access to new polyolefin architectures using Ziegler-Natta chemistry. Angew. Chem. Int. 2002, 41, 2236-2257. [CrossRef] 
34. IMeshkova, N.; Ushakova, T.M.; Gul'tseva, N.M.; Larichev, M.N.; Ladygina, T.A.; Kudinova, O.I. Influence of the catalyst matrix structure of the supported Ziegler-Natta catalysts on the homo- and copolymerization of olefins. Polym. Bull. 1997, 38, 419-426. [CrossRef]

35. Soga, K.; Yanagihara, H.; Lee, D. Effect of monomer diffusion in the polymerization of olefins over Ziegler-Natta catalysts. Makromol. Chem. 1989, 190, 995-1006. [CrossRef]

36. Van Grieken, R.; Carrero, A.; Suárez, I.; Paredes, B. Effect of 1-hexene comonomer on polyethylene particle growth and kinetic profiles. Macromol. Symp. 2007, 259, 243-252. [CrossRef]

37. Ko, Y.S.; Woo, S.I. Shape and diffusion of the monomer-controlled copolymerization of ethylene and $\alpha$-olefins over $\mathrm{Cp}_{2} \mathrm{ZrCl}_{2}$ confined in the nanospace of the supercage of NaY. J. Polym. Sci. A 2003, 41, 2171-2179. [CrossRef]

38. Soga, K.; Ohgizawa, M.; Shiono, T.; Lee, D. Possibility of mass-transfer resistance in ethylene polymerization with $\mathrm{MgCl}_{2}$-supported catalysts. Macromolecules 1991, 24, 1699-1700. [CrossRef]

39. Przybyla, C.; Tesche, B.; Fink, G. Ethylene/hexene copolymerization with the heterogeneous catalyst system $\mathrm{SiO}_{2} / \mathrm{MAO} / \mathrm{rac}-\mathrm{Me}_{2} \mathrm{Si}[2-\mathrm{Me}-4-\mathrm{Ph}-\mathrm{Ind}]_{2} \mathrm{ZrCl}_{2}$ : The filter effect. Macromol. Rapid Comm. 1999, 20, 328-332. [CrossRef]

40. Do Santos, H.Z.; Uozumi, T.; Teranishi, T.; Sano, T.; Soga, K. Ethylene (co)polymerization with supported-metallocenes prepared by the sol-gel method. Polymer 2001, 42, 4517-4525. [CrossRef]

41. Smit, M.; Zheng, X.; Bruell, R.; Loos, J.; Chadwick, J.C.; Koning, C.E. Effect of 1-hexene comonomer on polyethylene particle growth and copolymer chemical composition distribution. J. Polym. Sci. A 2006, 44, 2883-2890. [CrossRef]

42. Yoon, K.B.; Lee, D.H.; Noh, S.K. Copolymerization of ethylene and 1-hexene using (n-BuCp) ${ }_{2} \mathrm{ZrCl}_{2}$ catalyst activated by the cross-linked MAO supported cocatalyst. Macromol. Res. 2006, 14, 240-244. [CrossRef]

43. Spitz, R.; Pasquet, V.; Guyot, A.B. Linear low density polyethylene prepared in gas phase with bisupported $\mathrm{SiO}_{2}-\mathrm{MgCl}_{2}$ Ziegler-Natta catalysts. In Transtion Metals and Organometallics as Catalysts for Olefin Polymerization; Kaminsky, W., Sinn, H., Eds.; Springer: Berlin, Germany, 1988; pp. 405-416.

44. Barzan, C.; Bordiga, S.; Groppo, E. Towards the understanding of the comonomer effect on $\mathrm{CrII}_{/} / \mathrm{SiO}_{2} \mathrm{Phillips}$ catalyst. ACS Catal. 2016, 6, 2918-2922. [CrossRef]

45. Fan, Z.Q.; Yasin, T.; Feng, L.X. Copolymerization of propylene with 1-octene catalyzed by rac- $\mathrm{Me}_{2} \mathrm{Si}\left(2,4,6-\mathrm{Me}_{3}-\mathrm{Ind}\right)_{2} \mathrm{ZrCl}_{2} /$ methyl aluminoxane. J. Polym. Sci. A 2000, 38, 4299-4307. [CrossRef]

46. Quijada, R.; Guevara, J.L.; Galland, G.B.; Rabagliatid, F.M.; Lopez-Majada, J.M. Synthesis and properties coming from the copolymerization of propene with $\alpha$-olefins using different metallocene catalysts. Polymer 2005, 46, 1567-1574. [CrossRef]

47. Tait, P.J.T.; Berry, I.G. Rate Enhancement effects in the prepolymerization and copolymerization of ethylene and $\alpha$-Olefins. In Catalyst Design for Tailor-Made Polyolefins; Soga, K.M., Terano, M., Eds.; Elsevier-Kodansha: Tokyo, Japan, 1994; pp. 55-72.

48. Spitz, R.; Masson, R.; Bobichon, C.; Guyot, A. Propene polymerization with $\mathrm{MgCl}_{2}$ supported Ziegler catalysts: Activation by hydrogen and ethylene. Makromol. Chem. 1988, 189, 1043-1050. [CrossRef]

49. Forlini, F.; Fan, Z.Q.; Tritto, I.; Locatelli, P.; Sacchi, M.C. Metallocene-catalyzed propene/1-hexene copolymerization: Influence of amount and bulkiness of cocatalyst and of solvent polarity. Macromol. Chem. Phys. 1997, 198, 2397-2408. [CrossRef]

50. Kissin, Y.V.; Mink, R.I.; Nowlin, T.E. Ethylene polymerization reactions with Ziegler-Natta catalysts. I. Ethylene polymerization kinetics and kinetic mechanism. J. Polym. Sci. A 1999, 37, 4255-4272. [CrossRef]

51. Kissin, Y.V.; Brandolini, A.J. Ethylene polymerization reactions with Ziegler-Natta Catalysts. II. Ethylene polymerization reactions in the presence of deuterium. J. Polym. Sci. A 1999, 37, 4273-4280. [CrossRef]

52. Kissin, Y.V.; Mink, R.I.; Nowlin, T.E.; Brandolini, A.J. Ethylene polymerization reactions with Ziegler-Natta Catalysts. III. Chain-end structures and polymerization mechanism. J. Polym. Sci. A 1999, 37, 4281-4294. [CrossRef]

53. Xu, T.; Yang, H.; Fu, Z.; Fan, Z.-Q. Effects of comonomer on active centre distribution of $\mathrm{TiCl}_{4} / \mathrm{MgCl}_{2}-\mathrm{AlEt}_{3}$ catalyst in ethylene/1-hexene copolymerization. J. Org. Chem. 2015, 798, 328-334. [CrossRef]

54. Marques, M.F.V.; Marinha, A.B.A.S. Zeolite-supported metallocene catalyst for ethylene/1-hexene copolymerization. J. Polym. Sci. Part A Polym. Chem. Ed. 2004, 42, 3038-3048. [CrossRef] 
55. Forlini, F.; Princi, E.; Tritto, I.; Sacchi, M.C.; Piemontesi, F. ${ }^{13} \mathrm{CNMR}$ study of the effect of coordinating solvents on zirconocene-catalyzed propene/1-hexene copolymerization. Macromol. Chem. Phys. 2002, 203, 645-652. [CrossRef]

56. Heiland, K.; Kaminsky, W. Comparison of zirconocene and hafnocene catalysts for the polymerization of ethylene and 1-butene. Makromol. Chem. 1992, 193, 601-610. [CrossRef]

57. García-Peñas, A.; Martínez, C.; Cerrada, M.L.; Pérez, E.; Gómez-Elvira, J.M. NMR study of the comonomer effect in metallocene poly(propylene-co-1-pentene) copolymers synthesized at low temperature. J. Polym. Chem. Part A Polym. Chem. Ed. 2017, 55, 843-854. [CrossRef]

58. Mackay, D.; Shiu, W.Y.; Ma, K.-C.; Lee, S.C. (Eds.) Handbook of physical-chemical properties and environmental fate for organic chemicals. In Volume I. Introduction and Hydrocarbons, 2nd ed.; CRC Taylor \& Francis Group: Boca Raton, FL, USA, 2006; p. 311.

59. Villar, M.A.; Ferreira, M.L. Co-and terpolymerization of ethylene, propylene, and higher $\alpha$-olefins with high propylene contents using metallocene catalysts. J. Polym. Sci. A 2001, 39, 1136-1148. [CrossRef]

60. Busico, V.; Cipullo, R. Microstructure of polypropylene. Prog. Polym. Sci. 2001, 26, 443-533. [CrossRef]

61. Asakura, T.; Demura, M.; Nishiyama, Y. Carbon-13 NMR spectral assignment of five polyolefins determined from the chemical shift calculation and the polymerization mechanism. Macromolecules 1991, 24, 2334-2340. [CrossRef]

62. Usami, T.; Takayama, S. Fine-branching structure in high-pressure, low-density polyethylenes by $50.10-\mathrm{MHz}$ ${ }^{13} \mathrm{C}$ NMR analysis. Macromolecules 1984, 17, 1756-1761. [CrossRef]

63. Hoyos, M.; Tiemblo, P.; Gómez-Elvira, J.M.; Rychlá, L.; Rychlý, J. Role of the interphase dynamics in the induction time of the thermo-oxidation of isotactic polypropylene. Polym. Degrad. Stab. 2006, 91, 1433-1442. [CrossRef]

64. Resconi, L.; Camurati, I.; Sudmeijer, O. Chain transfer reactions in propylene polymerization with zirconocene catalysts. Top. Catal. 1999, 7, 145-163. [CrossRef]

65. He, Y.; Qiu, X.H.; Klosin, J.; Cong, R.; Roof, G.R.; Redwine, D. Terminal and internal unsaturations in poly(ethylene-co-1-octene). Macromolecules 2014, 47, 3782-3790. [CrossRef]

66. Busico, V.; Cipullo, R.; Friederichs, N.; Linssen, H.; Segre, A.; Van Axel Castelli, A.; Van der Velden, G. ${ }^{1} \mathrm{H}$ NMR analysis of chain unsaturations in ethylene/1-octene copolymers prepared with metallocene catalysts at high temperature. Macromolecules 2005, 38, 6988-6996. [CrossRef]

67. Resconi, L.; Piemontesi, F.; Camurati, I.; Balboni, D.; Sironi, A.; Moret, M.; Rychlicki, H.; Ziegler, R. Diastereoselective Synthesis, molecular structure, and solution dynamics of meso- and rac-[ethylenebis(4,7-dimethyl- $\eta^{5}$-1-indenyl)] zirconium dichloride isomers and chain transfer reactions in propene polymerization with the rac isomer. Organometallics 1996, 15, 5046-5059. [CrossRef]

68. Carvill, A.; Zetta, L.; Zannoni, G.; Sacchi, M.C. ansa-Zirconocene-catalyzed solution polymerization of propene: Influence of polymerization conditions on the saturated chain-end groups. Macromolecules 1998, 31, 3783-3789. [CrossRef]

69. Resconi, L.; Piemontesi, F.; Camurati, I.; Sudmeijer, O.; Nifant'ev, I.E.; Ivchenko, P.V.; Kuz'mina, G. Highly regiospecific zirconocene catalysts for the isospecific polymerization of propene. J. Am. Chem. Soc. 1998, 120, 2308-2321. [CrossRef]

70. Grumel, V.; Brüll, R.; Pasch, H.; Raubenheimer, G.; Sandersom, R.; Wahner, U.M. Homopolymerization of higher 1-olefins with metallocene/MAO catalysts. Macromol. Chem. Eng. 2001, 286, 480-487. [CrossRef]

71. Kawahara, N.; Saito, J.; Matsuo, S.; Kaneko, H.; Matsugi, T.; Toda, Y.; Kashiwa, N. Study on unsaturated structures of polyhexene, poly(4-methylpentene) and poly(3-methylpentene) prepared with metallocene catalysts. Polymer 2007, 48, 425-428. [CrossRef]

72. Rossi, A.; Odian, G.; Zhang, J. End groups in 1-butene polymerization via methylaluminoxane and zirconocene catalyst. Macromolecules 1995, 28, 1739-1749. [CrossRef]

73. Busico, V.; Carbonniere, P.; Cipullo, R.; Pellecchia, R.; Severn, J.R.; Talarico, G. Alk-1-ene polymerization in the presence of a monocyclopentadienyl zirconium(IV) acetamidinate catalyst: Microstructural and mechanistic insights. Macromol. Rapid Commun. 2007, 28, 1128-1134. [CrossRef]

74. Bomfim, J.A.S.; Dias, M.L.; Filgueiras, C.A.L.; Perch, F.; Deffieux, A. The effect of polymerization temperature on the structure and properties of poly(1-hexene) and poly(1-decene) prepared with a $\mathrm{Ni}$ (II)-diimine catalyst. Catal. Today 2008, 133-135, 879-885. [CrossRef] 
75. Cheng, H.N.; Smith, D.A. 13C NMR studies of low-molecular weight ethylene-propylene copolymers and characterization of polymer chain ends. Macromolecules 1986, 19, 2065-2072. [CrossRef]

76. Resconi, L.; Piemontesi, F.; Franciscono, G.; Abis, L.; Fiorani, T. Olefin polymerization at bis(pentamethylcyclopentadienyl)zirconium and hafnium centres: Chain-transfer mechanisms. J. Am. Chem. Soc. 1992, 114, 1025-1032. [CrossRef]

77. Bader, M.; Marquet, N.; Kirilov, E.; Roisnel, T.; Razavi, A.; Lhost, O.; Carpentier, J.F. Old and new $C_{1}$-symetric group 4 metallocenes $\left\{\left(R^{1} R^{2} C\right)-\left(R^{2^{\prime}} R^{3^{\prime}} R^{6^{\prime}} R^{7^{\prime}}-\mathrm{Flu}\right)\left(3-\mathrm{R}^{3}-5-\mathrm{R}^{4}-\mathrm{C}_{5} \mathrm{H}_{2}\right)\right\} \mathrm{ZrCl}_{2}$ : From highly isotactic polypropylenes to vinyl end-caped isotactic-enriched oligomers. Organometallics 2012, 31, 8375-8387. [CrossRef]

78. Moscardi, G.; Resconi, L.; Cavallo, L. Propene polymerization with the isospecific, highly regioselective rac- $\mathrm{Me}_{2} \mathrm{C}(3-\mathrm{t}-\mathrm{Bu}-1-\mathrm{Ind})_{2} \mathrm{ZrCl}_{2} / \mathrm{MAO}$ catalyst. 2. Combined DFT/MM analysis of chain propagation and chain release reactions. Organometallics 2001, 20, 1918-1931. [CrossRef]

79. Janiak, C. Metallocene and related catalysts for olefin, alkyne and silane dimerization and oligomerization. Coord. Chem. Rev. 2006, 250, 66-94. [CrossRef]

80. Schaverien, C.J.; Ernst, R.; Schut, P.; Dall'Occo, T. Ethylene bia(2-indenyl) zirconocenes: A new class of diastereomeric metallocenes for the (co)polymerization of $\alpha$-olefins. Organometallics 2001, 20, 3436-3452. [CrossRef]

81. Hajela, S.; Bercaw, J.E. Competitive chain transfer by $\beta$-Hydrogen and $\beta$-methyl elimination for the model Ziegler-Natta olefin polymerization system $\left[\mathrm{Me}_{2} \mathrm{Si}\left(\eta^{5}-\mathrm{C}_{5} \mathrm{Me}_{4}\right)_{2}\right] \mathrm{Sc}\left\{\mathrm{CH}_{2} \mathrm{CH}\left(\mathrm{CH}_{3}\right)_{2}\right\}\left(\mathrm{PMe}_{3}\right)$. Organometallics 1994, 13, 1147-1154. [CrossRef]

82. Guo, Z.; Swenson, D.; Jordan, R.F. Cationic zirconium and hafnium isobutyl complexes as models for intermediates in metallocene-catalyzed propylene polymerizations. Detection of an $\alpha$-agostic interaction in $\left(\mathrm{C}_{5} \mathrm{Me}_{5}\right)_{2} \mathrm{Hf}\left(\mathrm{CH}_{2} \mathrm{CHMe}_{2}\right)\left(\mathrm{PMe}_{3}\right)+$. Organometallics 1994, 13, 1424-1432. [CrossRef]

(C) 2019 by the authors. Licensee MDPI, Basel, Switzerland. This article is an open access article distributed under the terms and conditions of the Creative Commons Attribution (CC BY) license (http://creativecommons.org/licenses/by/4.0/). 